\title{
THE IMPACT OF VALUE CHAINS ON POPULATION HEALTH ACROSS DEVELOPING COUNTRIES
}

by

Guneet Kaur Sawhney

B.E., Thapar Institute of Engineering and Technology, India, 2016

\author{
A thesis \\ presented to Ryerson University \\ in partial fulfillment of the requirements for the degree of \\ Master of Science in Management \\ in the program of \\ Master of Science in Management
}

Toronto, Ontario, Canada, 2020

(C) Guneet Kaur Sawhney, 2020 


\section{Author's Declaration}

I hereby declare that I am the sole author of this thesis. This is a true copy of the thesis, including

any required final revisions, as accepted by my examiners.

I authorize Ryerson University to lend this thesis to other institutions or individuals for the

purpose of scholarly research.

I further authorize Ryerson University to reproduce this thesis by photocopying or by other

means, in total or in part, at the request of other institutions or individuals for the purpose of scholarly research.

I understand that my thesis may be made electronically available to the public. 


\begin{abstract}
Guneet Kaur Sawhney

Master of Science in Management (MScM)

Master of Science in Management

Ryerson University
\end{abstract}

The impact of value chains on population health across developing countries

2020

This study examines how value chains influence health of the population in the presence of several other socio-economic determinants. Based on the cross-sectional panel data available for developing nations, we apply feasible generalized least squares regression models to investigate the relationship between value chains and health of the population. The results suggest that value chains can improve population health outcomes significantly. For example, an increase in value chain breadth by $1 \%$ results in a decrease in infant and maternal mortality rates by 0.16 and 1.4 , respectively. In a sector of human capital development, the findings provide potential guidance for the growth of firms to improve population health. 


\section{Acknowledgement}

I owe my deepest gratitude to my supervisor Dr. Hossein Zolfagharania for giving me the opportunity to work on this thesis. This project would not have been possible without his encouragement, support and guidance. I attribute the completion of my work from initial to the final level to his encouragement and effort. I also thank Dr. Julien Meyer and Dr. Vik Singh for their early involvement and guidance as my external examiners. I also wish to thank my mother for giving me strength during the completion of this project. I also extend my gratitude to my colleagues, Saman Feroze and Rijuta Menon, for encouraging and motivating me throughout this project. 


\section{Table of Contents}

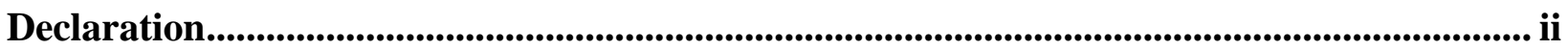

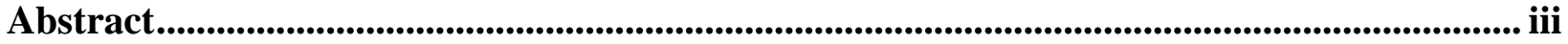

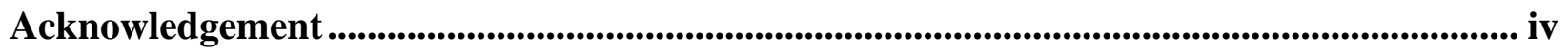

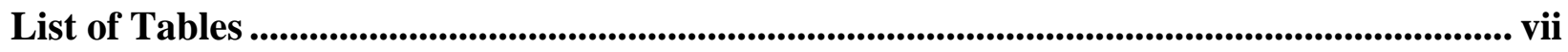

List of Figures............................................................................................................................................ viii

Chapter 1 Introduction.............................................................................................................................1

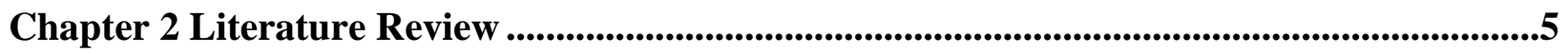

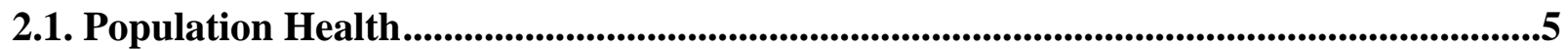

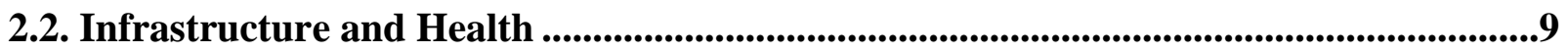

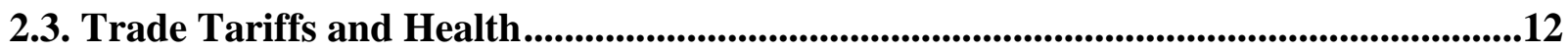

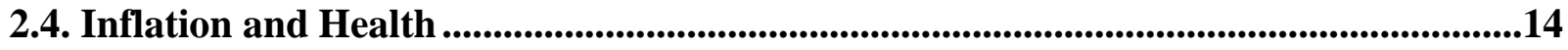

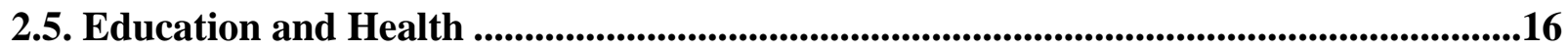

2.6. Universal Health Coverage and Health .................................................................................18

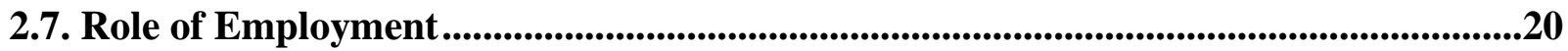

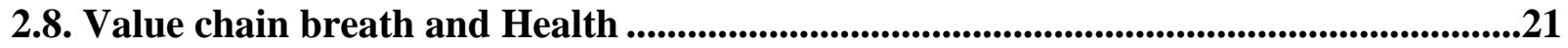

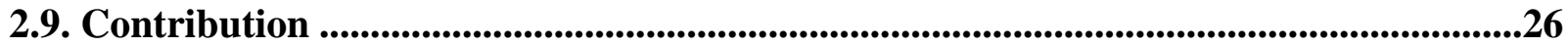

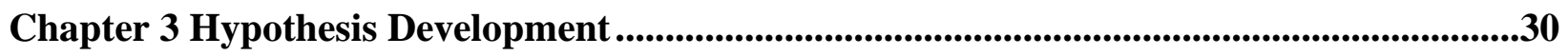

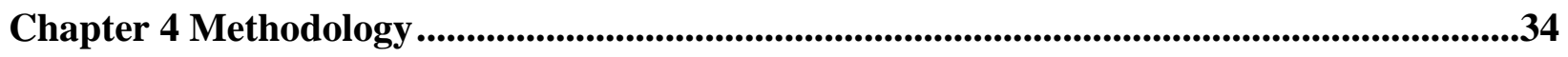

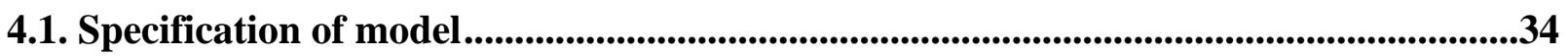

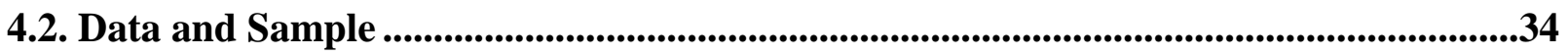

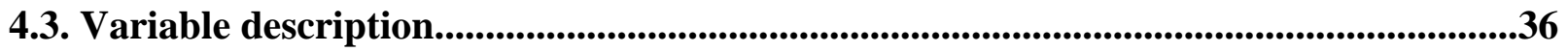

4.3.1. Dependent variables ..........................................................................................................36

4.3.2. Independent variables .......................................................................................................38

4.4. Method 
Chapter 5 Analysis and Results

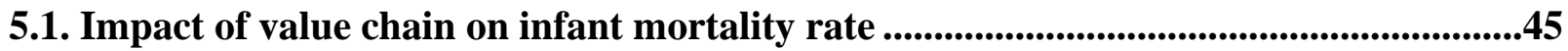

5.2. Impact of value chain on maternal mortality rate ..............................................................47

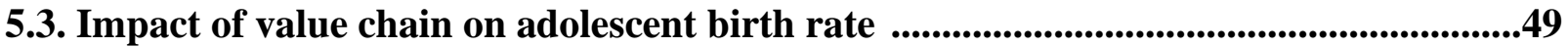

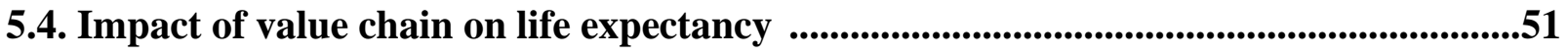

Chapter 6 Implications, limitations, future research and conclusion ..................................54

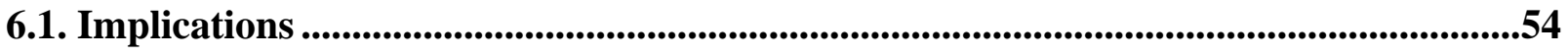

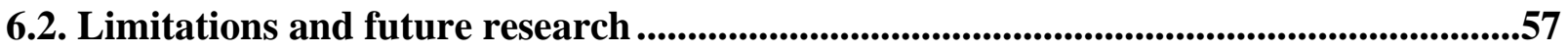

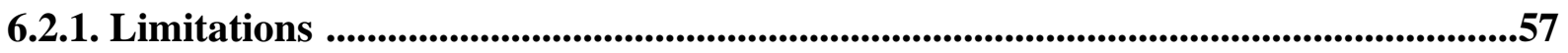

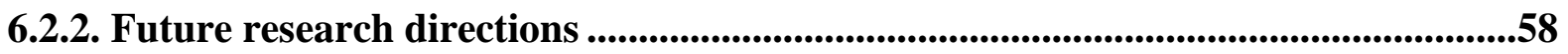

6.3. Conclusion

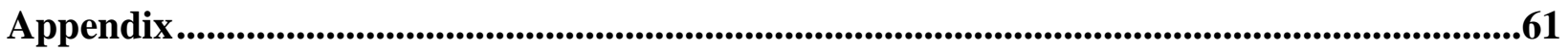

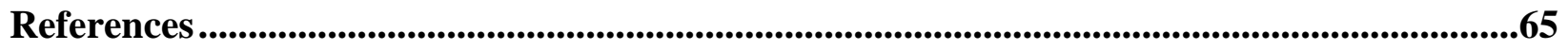




\section{List of Tables}

Table 1 Socioeconomic determinants of health .......................................................................26

Table 2 Impact of value chain on infant mortality rate ..........................................................46

Table 3 Impact of value chain on maternal mortality rate ................................................48

Table 4 Impact of value chain on adolescent birth rate .....................................................50

Table 5 Impact of value chain on life expectancy .................................................................52 


\section{List of Figures}

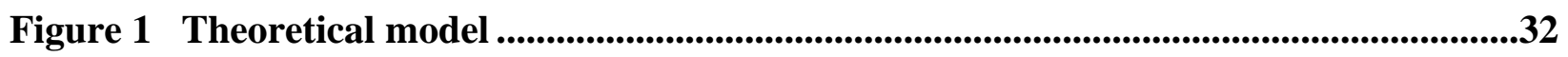




\section{Chapter 1}

\section{Introduction}

Population health is gaining worldwide attention and is a topic of major concern for most of the developing nations. The four indicators used as a proxy for population health such as infant mortality rate, maternal mortality rate, adolescent birth rate and life expectancy at birth have been on the top priority of the World Health Organization to strengthen community health for the development of the human capital and economic development of the nation. As per the statistics, a large proportion of maternal deaths take place in developing nations. According to the World Bank, about 500,000 pregnant mothers die every year in developing countries (World Bank, 2007). Due to the alarming situation, world organizations have been making consistent efforts in helping countries reduce maternal health risks. Maternal mortality ratio is reportedly high in the least developed nations; about 415 deaths per 100,000 live births, which is approximately 60 times higher than in Australia and New Zealand and 40 times higher than in Europe (WHO, UNICEF, UNFPA, World Bank Group, \& United Nations Population Division, 2019). Another critical determinant of population health is the adolescent fertility rate. Reports suggest that countries with high adolescent fertility rates fall in the risk of high maternal, infant and child mortality (The World Bank, 2019). Since the adolescent birth rate is also high in countries with high fertility rates, the risk of death among adolescents is also high. Moreover, newborns to adolescents also suffer from low birth weights, poor health and nutritional outcomes (The World Bank, 2019). Reports reveal that in Sub-Saharan Africa, more than a fourth of teenage girls and women do not have access to family health programs and services that leads to unplanned pregnancies, infant and child mortality and maternal mortality (The World Bank, 2019). Moreover, maternal mortality rates among 
teenage girls (below 18 years of age) are 2 to 5 times higher in women in the age group of 18-25 (World Bank, 2007). As per the World Health Organization, the adolescent birth rate is 44 per 1000 girls aged 15-19 years (World Health Organization, 2016). About 2.7 million infants died in the year 2015 globally within the first 28 days of birth, with $73 \%$ of the deaths occurring in the first week of birth (World Health Organization, 2015). As the overall mortality rate of the population is explained by life expectancy at birth, it is one of the major health concerns for the economic development of the country. As per the sources, life expectancy at birth ranged from 61 years in Africa to 77 years in Europe in 2016 (World Health Organization, n.d.). There was an increase in the average life expectancy at birth by 5.5 years from 2000 to 2016 globally, where the African region recorded an increase of 10.3 years primarily because of improvement in child survival. This has been recorded as the fastest increase since 1960 (World Health Organization, n.d.).

Several socio-economic reasons account for the health of the population, the most important being the ability to afford necessities such as food, shelter and clothing. High unemployment and socioeconomic conditions have been the point of major concern for policymakers (Schwab, 2012). Filthy housing conditions, high unemployment and limited access to basic services lead to poor health (Wilkinson and Marmot, 2003). Value chains comprise of a range of activities from suppliers to manufacturers to consumers. The breadth of the chain is defined in terms of firms' presence in the value chain. Firms investing in upper parts of the chain such as manufacturing or extraction of raw materials have a narrow presence in the value chain whereas firms investing in distribution, design and warehousing have a broader presence in the chain (World Bank, 2017).Value chains can be a source of employment generation, which raises the economic productivity of the workforce (Farole et al., 2018). The creation of jobs ranges from those that 
require a skilled workforce to those with low skilled workers. For example, Nokia, the largest electronics manufacturer in Finland, developed the Finnish economy (Ainamo, 1997). Finland though a developed economy, was developed by the firm Nokia in the year 1865. Nokia started manufacturing electronics and slowly expanded the business to the processing of plastics and chemicals. This helped the Finnish economy flourish as this raised their household income and opened the door to economic opportunities. On the contrary, it is also justifiable that, firms could also expand capital intensively by investing in labor-saving technologies and not hiring people (Farole et al., 2018). For instance, a firm in Brazil grew capital intensively through technological intervention and fully mechanized production mechanisms. This led to the substitution of labor. This is contrary to the labor-intensive production, where expansion could create employment opportunities. Although a firm moves up the value chain labor intensively or capital intensively, the study on value chains is essential because they help in improving the health of the population, development of human capital and growth of the economy. Therefore, our study focusses on the relationship between a value chain and population health.

In our study, we are capturing population health as a measure of four variants, namely infant mortality rate, maternal mortality ratio, adolescent birth rate and life expectancy at birth. Numerous studies covered the socioeconomic determinants of health (Calderón and Servén, 2004; Snieška and Šimkūnaitè, 2009; Pierce and Schott, 2016; Ha et al., 2019). Apart from socioeconomic factors such as infrastructure, inflation, trade, employment and education, which largely affect the health of the population, certain factors could also determine population health to a large extent. One such parameter captured by the World Bank as a measure of economic productivity of the country is value chain breadth. It is defined as the firms which have a smaller or broader presence in the value chain for instance, firms involved only in production tend to have a smaller 
presence in the value chain against the firms that are also involved in distribution and design. Our study determines the impact of value chain breadth on the population health in the presence of employment rate as an interaction parameter.

The rest of this thesis is organized as follows. Chapter 2 provides an overview of the relevant literature. Chapter 3 focusses on the development of hypothesis. Chapters 4 highlights the data collection process and method of analysis. Chapter 5 focusses on the analyses and results. Chapter 6 outlines the discussion of results, limitations, future research directions and conclusions. 


\section{Chapter 2 \\ Literature Review}

Several researchers captured the socio-economic determinants of health, such as public infrastructure, which includes transport, power, trade liberalization, inflation dynamics and education. Our study contributes to the literature by examining the impact of value chains on population health. There are six factors described in the study that might have an impact on population health. The literature has been organized into eight sub-sections. Each subsection describes one potential factor and explains its potential influence on the health of the population. Subsection 1 defines the health of the population and its proxy measures used in the study. Subsection 2 focusses on the relationship between infrastructure and population health. Subsection 3 describes the importance of trade in improving population health outcomes. Subsection 4 illustrates the role of inflation in determining population health, while Subsections 5 and 6 determine the importance of education and Universal Health Coverage in improving population health respectively. Then, Subsection 7 reflects on the role of employment in improving health outcomes, and lastly Subsection 8 focusses on the importance of value chains and how they could impact the population health. After reviewing the literature, we summarize the contributions of our study and point out its novelty.

\subsection{Population Health}

Health is an important aspect that has gained worldwide attention. Countries throughout the world have been focussing on their respective health care problems and devising possible solutions for quality living. Though advanced technology in the healthcare sector has improved the health of the economy, some of the root problems still revolve around the socioeconomic status of the 
population. Economies have been struggling to attain a healthy life for individuals. Some of the common health indicators explained by the World Health Organization include infant mortality rate, maternal mortality ratio, life expectancy and adolescent birth rate (World Health Organization, 2015). Both child mortality and maternal mortality are the development goals as specified by the World Bank closely associated with food and nutrition (World Bank, 2012). It was also reported that 105 out of 144 countries are lagging to reduce child mortality and 94 countries are off track the goal to reduce maternal mortality.

Infant mortality rate is defined as the number of deaths of children under the age of 1 per 1000 live births (Mathews et al., 2015). It is considered as an indicator of a country's overall health (Government of Canada, 2008). As countries strive to achieve healthier populations, the infant mortality rate is considered as a tool to measure the health status of the country. The statistics reveal that every year, around 4 million children die before they are a month old and $98 \%$ of these deaths take place in developing nations (World Health Organization, 2005). As per the World Health Organization, infant mortality rate is defined as the probability of infant born in a year dying before the age of one. It is specified that infant mortality is not a rate, but a probability expressed in terms of 1000 live births (World Health Organization, WHO statistical information system, 2016). It is also considered as the most important indicator to capture the overall development of the country (World Health Organization, WHO statistical information system, 2016). Apart from the world organizations such as WHO, some of the state health departments also consider infant mortality rate as a crucial health status indicator to measure the health of the population (New Jersey Department of Health, 2019). Navarro et al. (2006) discussed the impact of political outcomes on population health. The population health variables used in the study were infant mortality rate and life expectancy at birth obtained from World Bank. A general measure 
for population health highlights the countries in need of improving the living conditions and social well being of the population.

One of the development goals listed by the World Health Organization is to enhance maternal health and reduce the maternal mortality ratio. This is to ensure the health and well-being of people of all ages. Maternal mortality ratio is defined as the death of a woman when pregnant or within 42 days of termination of pregnancy irrespective of any reason related to pregnancy or its management. This does not include unintentional or incidental causes. It is recorded as the number of maternal deaths during a given time period per 100000 live births during the same time frame (WHO, UNICEF, UNFPA, World Bank Group and United Nations Population Division, 2019). As reported by the World Health Organization, care required during childbirth has always been considered as a household affair limited to mothers. This continued for many centuries. While in the $20^{\text {th }}$ century, the concern for the healthcare sector, especially the health of mothers and children, drifted from a domestic responsibility to a population health priority. The whole concept revolves around a societal notion that newborns are the future of society, which is shaped by their mothers as they are nurtured. Mothers play a variety of roles, such as they are caregivers and homemakers; they follow the cultural norms and traditions that are carried forward to families and communities. They shape the future of their child and contribute to his health and development. For these reasons, the nation takes into account the health of mothers and children (World Health Organization, 2005). Moreover, data provided by the WHO states that less than $1 \%$ of maternal deaths occur in high-income countries (World Health Organization, 2005). Maternal deaths in developing nations are attributed to the social status of women, economic resources and infrastructure of the countries. 
Life expectancy at birth highlights the population mortality levels. It captures the pattern of mortality across people of all ages. Life expectancy is measured as the average number of years a newborn is expected to live irrespective of the current mortality rates (World Health Organization, WHO statistical information system, 2016). It is one of the critical predictors of the health of the nation (Government of Canada, 2016). Life expectancy at birth is influenced by certain factors such as living conditions, diet and education. Judge (1995) reported life expectancy as one of the prime indicators of population health and economic development. In countries such as England and Wales, life expectancy was used as an indicator of population health status (London: Office for National Statistics, 2003). One of the studies measured the impact of income inequality and education on population health. The population health indicator used in the study was life expectancy at birth (De Vogli et al., 2005). Apart from being a health indicator, life expectancy at birth is also used as a proxy to measure the socioeconomic development of the nation (The World Bank, n.d.). Judge et al. (1998) conducted research on rich industrialized countries to measure the relationship between income distribution and population health outcomes such as infant mortality and life expectancy at birth. The results suggest that a positive association exists between infant mortality and income distribution at $90 \%$ level of significance and there is no statistically significant relationship between income inequality and life expectancy at birth.

Apart from mortality rates and life expectancy, adolescent birth rate is also recognized as the health indicator by the World Bank. It is defined as the number of kids born to women aged 15-19 years per 1000 women in the same age group in 1 year. The adolescent birth rate is also called a fertility rate. It is calculated as a ratio. The fertility rate is the number of live births to women age 15-19 years, divided by an estimate of exposure to childbearing by women of the same age group (World Health Organization, 2013). World Organizations have been focussing on adolescent fertility rates 
to improve the social and economic well being of adolescents. It is considered as a major concern because women who give birth when they are young are prone to a greater risk of complications, which may lead to death during pregnancy and birth. In addition, children born to women who are very early in their reproductive lives are vulnerable and may encounter certain health issues. Poor people experience higher birth rates among adolescents. This is primarily because poor teenage girls have limited access to reproductive health services, adequate schooling and economic opportunities (World Bank, 2007). Hence, reducing adolescent fertility is important to enhance maternal health and reduce infant mortality rate (World Health Organization).

\subsection{Infrastructure and Health}

Households and businesses both rely on infrastructural development of the nation. The decision to invest in infrastructure depends on its availability and quality. Availability and accessibility to infrastructure services play an essential role in the development of countries and areas. Infrastructure services are delivered at the advantage of physical infrastructure. The extent of investment in infrastructure gives rise to inequalities between nations. Calderón and Servén (2004) supported the fact that certain countries experienced the pressure of reducing debts, which led to a reduction in the expenditure on public infrastructure. This reduction was not covered by the increase in private sector involvement. Hence, this exposed the countries to lack of availability of infrastructure services hampering economic growth and giving rise to inequality. Infrastructure induces economic growth by influencing the education and health parameters positively (Snieška and Šimkūnaitè, 2009). The quality of infrastructure is important because it is used as a final consumption item by people and as intermediate consumption item by firms (Snieška and Šimkūnaitè, 2009). 
The services that are crucial to the day-to-day activities of the public and economic productivity include power, availability of water and sanitation, transport and telecommunications. Snieška and Šimkūnaitè (2009) categorized transportation, water supply and disposal, telecommunications and power infrastructure as public infrastructure because a large number of consumers are benefitted from them. Several studies stated that public infrastructure supports the quality of living, for example, good quality road network reduces casualties and enhance the safety of the public, expansion of safe water systems help in the reduction of diseases, management of waste and disposal results in the improvement of environmental health and aesthetics (Aschauer, 2000). Snieška and Šimkūnaitè (2009) also elaborated on the same idea of how investing in infrastructure services promotes growth. They emphasized on the development of human capital, especially health and education, which depend on access to supportive infrastructures such as water and sanitation to avert diseases, electricity to support schools and health establishments and roads to access them.

Infrastructure services make productive opportunities accessible for poor households by connecting poor individuals and less developed areas to economic activities. Transport facilitates the mobility of goods, people and ideas all around the world and makes economic opportunities, for example, jobs accessible. The development of infrastructure can also influence the employment opportunities and income probability of the poor disproportionately. This refers to both education and health; health is the most important factor (Calderón and Servén, 2004). The author further revealed that changes in policy, enhance the infrastructure quality and improve the availability of resources for poor in developing nations that has a substantial and positive impact on their health, well being, and education and thus their income and welfare. The idea of enhancement of income and welfare is supported by Snieška and Šimkūnaitè (2009), who justified that infrastructure 
accessibility and quality results in time and cost savings, ensures safety, development of information networking and employment and economic growth. Furthermore, school attendance levels could be increased through deployment of safe road network and an excellent transport facility. The number of hours of study could be attributed to power infrastructure specifically electricity.

Focussing on the health sector, Calderón and Servén (2004) justified that accessibility to water and sanitation can not only improve the health of individuals but also help in the significant reduction of child mortality. A piece of clear evidence reported by the study involved a case from Argentina, where increased availability of water and sanitation reduced child mortality by $8 \%$, with a greater portion of the reduction occurring in low-income regions. A study by Agénor and Moreno-Dodson (2006) stressed on the importance of infrastructure services in improving the health and education of the population and their long-term impact on national welfare. Calderón and Servén (2004) assessed the impact of the quality of overall infrastructure on growth using the data from 121 countries spanning over 1960-2000. They developed an index comprising of three indicators: quality service of telecommunications (waiting line for main telephone lines), power (percentage of transmission and distribution losses in the production of electricity) and transport (the share of paved roads in total roads). The relationship between the index and growth was reported using the Generalized Method of Moments (GMM) method. The results signify that infrastructure positively impacts growth. However, as suggested by Snieška and Šimkūnaitè (2009) and Calderón and Servén (2004), infrastructure enhances the health of the society and hence promotes growth and welfare. 


\subsection{Trade Tariffs and Health}

Liberalization of trade can affect health in different ways. The impact can be both direct and indirect. In a very rare situation, the effect is direct, and the consequences are apparent, for example, when a disease is transferred across the border along with the traded substance (World Health Organization and World Trade Organization, 2002). Most of the time, the indirect impact of trade liberalization rules the economy. For instance, a reduction in trade tariffs can result in a drop in the price of medical equipment or products related to health care such as vaccines and medicines. Reduction in tariffs can also lead to a change in rules for patent protection, which can improve access to essential medicines and can facilitate technology transfer (Blouin et al., 2005). There exists an association between higher trade and economic growth, which leads to improved health and higher living standards (Blouin et al., 2005). The author further justified that greater trade in the health sector results in the movement of resources, which leads to greater benefits beyond the health domain. The countries with greater availability of health professionals can support the temporary movement of health professionals.

Moreover, trade liberalization results in development that leads to improved population health status. The health of the country depends on cross border trade and trade policies (tariffs). Trade policies affecting health status not only capture the effects it has on the health systems but also the impact it has on social, environmental and economic determinants of health. Although health systems are considered a crucial determinant of health, they are not the primary predictor of the health status of the population, especially for developing nations. Instead, the prominent determinants of population health are nutrition, accessibility to safe and clean water and sanitation, education and income (and hence employment). (World Health Organization and World Trade Organization, (2002) focussed on food security and malnutrition and how trade liberalization can 
help eradicate the problem. Malnutrition in pregnant women can lead to maternal mortality and infant mortality and morbidity.

Food security is defined at the national and household levels. The ability of a country to satisfy the nutritional requirements of the population by enough supply of food through food imports and national production is called national food security (World Health Organization and World Trade Organization, 2002). Furthermore, the ability of the household to make food accessible to all the members is called household food security. Increased trade and reduction in tariffs can help in making food available nationally by reducing the prices of consumer goods, especially prices of food, which make up a larger portion of expenditure for poor people (World Health Organization and World Trade Organization, 2002). On the contrary, WHO justified that with an increase in trade, infectious diseases can also spread as they depend on the movement of people, international trade of food products and social changes (World Health Organization and World Trade Organization, 2002).

Cross border trade or trade openness has an impact on the health of populations and national economies (Smith, 2006). The economic growth and development of the nation are highly dependent on trade. In his study, the author constructed an index for trade openness (as a measure of the level of restriction to trade) and analyzed its relationship with health and economic determinants. The approach used for analyzing the panel data was the fixed effects model. The results suggest that higher the openness index lower the mortality of the country.

As suggested by Panda (2015), trade not only enhances the economic growth of a country but also influences the socio-economic factors by increasing employment opportunities and skilled workforce. Increasing employment could not only improve the financial status of mothers but also positively impact the health of the child. An increase in household income would improve the 
quality of life through better nutrition and greater access to healthcare. Another impact of trade is reflected through an increase in tax revenues by the government, which would, in turn, lead to higher expenditure on health care. Improved cross-country trade can decrease the cost of transportation that would directly drop the costs of the imported goods. Levine and Rothman (2006) reported that an increase in trade as a percentage of GDP by around 15 percentage points decreased the number of infants dying by four. A few researchers reported that the ill distribution of resources has led to an increase in infant mortality rate (Pampel and Pillai, 1986). Considering the trade liberalization and how it can impact the health of the country, Pierce and Schott (2016) argued that rising competition of imports can positively or negatively affect the health of the workers in the United States. Nevertheless, the effect depends on the field of employment. Population health improves with a decrease in the prices of goods and services and with a rise in real income. However, health could deteriorate in regions where competition for the imports is higher and workers are exposed to a shortfall in employment and income. Additionally, liberalization of trade helps the economy grow by reducing poverty, improving the standard of living by creating ample export opportunities and increasing access to international markets and attracting a low cost of imports. This helps in the advancement of technology and medical help. Moreover, trade improves the nutritional status of the population by making the food available, accessible and affordable (Friel et al., 2013).

\subsection{Inflation and Health}

A rise in inflation relates to a drop in growth and a financial crisis. Li and Zou (2002) explained the impact of inflation on income inequality, which profoundly impacts the poor. The authors explain that when inflation occurs, the prices of consumer goods and services tend to increase ahead of an increase in money wages. Hence, inflation results in an income shift from those who 
rely on wages to profits. Because of this, inflation relatively hurts the poor more than the rich. The poorer households are affected the most with the hike in prices and the rise in inflation. This is because a significant portion of their household income is spent on food. According to the World Bank (2019), poor households are affected disproportionately due to the damage caused by high inflation. This is because they rely more on income earned from wages, do not have enough access to the accounts, which provide interests and have fewer chances to have a significant share in financial or real assets besides cash. The limited accessibility to food for poor households, their dependence on wage income and financial insecurity govern the growth and development of the economy. These rationales account for an association between low and stable inflation and higher economic developments and growth, reduction in poverty and financial stability (The World Bank, 2019). An increase in inflation has drawn the attention of both national and regional governments. A sudden and unstable rise in food prices increases the risk of food security. Unexpected hike in the consumer food prices results in the reduction of purchasing power of the population. This is because households find it difficult to accommodate the rise in prices and subsequently adjust by cutting down the calorie intake and nutrition. This gives rise to malnutrition and pushes more people towards hunger and poverty. Malnourishment, on the other hand, made people prone to diseases, which resulted in ill health. The condition of people being malnourished due to a rise in inflation is more prominent for poor households in urban settings and households who depend on women (The World Bank, 2019). The primary reason for this is that women and poor households in urban locations spend more than half of their income on food and they tend to reduce the consumption of required diet in the face of higher prices. Because of inflation, households suffer in the face of a reduction in their purchasing power. Consumers find it difficult to purchase the minimum number of calories and a staple diet as a result of rising food prices. This results in 
people shifting to less nutritious food and poor health. According to World Bank (2019), malnutrition in pregnant mothers holds a substantial share (more than a fifth) of maternal mortality. Evidence revealed that when Tanzania was hit by rising inflation (approximately $18 \%$ ), the number of households in the low-income group dropped by $20 \%$.

Moreover, there was a considerable drop in the consumption of nutritious food items. Rising inflation and commodity prices also affected the economic situation of the citizens. The citizens who thought that the economic situation of the country was worse increased from $65.7 \%$ to $85.7 \%$. Hence, a rise in inflation lowers economic growth. This is consistent with the findings of Li and Zou (2002), who conducted a cross-country analysis including Organisation for Economic Cooperation and Development (OECD) countries (Asian and Latin American) to study the impact of inflation on economic growth and income distribution. The results suggested that the rise in inflation results in the disproportionate distribution of income amongst the population; it results in a hike in the income share of the rich, negatively and decreases economic growth. However, $\mathrm{Li}$ and Zou (2002) reported that inflation rise has a negative impact on the income of the poor, but the impact was insignificant.

\subsection{Education and Health}

Education is an essential determinant of health and economic prosperity. It is one of the crucial factors important for social and economic development in developing countries (Petrosino et al., 2012). Education (especially for girls) is given prime importance because it governs reduction in infant mortality rates, improves child nutrition and school enrollment rates. As per statistics, above 100 million children (of primary school age) are devoid of primary schooling; about half of them are from the African region. According to the World Health Organization, in all societies, the poor and low-income countries bear the greatest risks to health and well-being (World Health 
Organization, 2002). Moreover, the poor and the disadvantaged groups, especially those with little education more commonly experience the threat to personal health (World Health Organization, 2002). World Organizations have been stressing to minimize gender disparities and make primary education available equally for both boys and girls and in all societies (UNESCO, 2007). Nations have been struggling to achieve universal access to primary education. Evidence based on the surveys conducted in Sub-Saharan African nations revealed that educational acquirement has a great impact on social outcomes (Mingat and Majgaard, 2012). The study further elaborated that each additional year of education has a positive association with social welfare. This could be explained by an example; women who completed a greater number of years of schooling are more likely to receive medical treatment and care during pregnancy and hence, this would result in a low maternal mortality ratio (Mingat and Majgaard, 2012). Therefore, education creates a strong foundation for better household health. A positive and significant association between education and health leads to economic development. Ross and $\mathrm{Wu}(1995)$ argued that people who are well educated possess good health than the people who are poorly educated or who did not receive any schooling. This is because educated people reported higher levels of physical health and decreased rates of morbidity, mortality and disability.

On the contrary, people who spent less number of years at school are prone to higher levels of risk of infectious diseases, chronic health problems, low rates of survival during sickness and a shorter life span. Ross and Wu (1995) further elaborated on the economic perspective of education. Educated people are more likely to be employed and least likely to experience financial hardship to afford a healthy living as compared to the ones who are less educated or the ones with no education. The findings from the study suggested that education leads to good health. An investment in the education sector is expected to result in the reduction of poverty, better health 
outcomes and growth of the economy (UNESCO, 2007). Consistent with this, Leigh (1983) argued that years of schooling represent good health and the health of the person is improved with an increase in expenditure on education at both national and state levels. The author also presented findings on the direct and indirect impact of education on population health. The author identified appropriate use of medical care as the direct effect and the role of education in influencing healthy eating habits as an indirect impact. Further, the findings suggested that the indirect impact of education overpowers the direct effect. This implies that basic education provides access to better food and nutrition that impacts the health of the public.

Another health outcome, depending on education, discussed by World Bank (2007) is the teenage childbearing rate. This is most common in developing nations. According to the data reported by (World Bank, 2007), in countries such as Sub-Saharan Africa, South Asia, and Latin America, greater than $10 \%$ of teenage girls are mothers. Furthermore, in Bangladesh and Mozambique, the number is more than $30 \%$. Incompletion of primary education (early school dropouts), financial insecurity and lower wages are the factors that lead to higher adolescent fertility rates. Therefore, nations particularly monitor the fertility rates amongst women aged between 15-19 years for economic development.

\subsection{Universal Health Coverage and Health}

Some of the socio-economic factors such as income, inflation and employment pose as barriers for the general public to receive adequate health care. Because of this, the World Health Organization targets to make Universal Health Coverage accessible and available to all economies. In order to enhance the well being of the general public of a country's population, it is required that all people, rich or poor, can receive health care services when required without experiencing any financial hardship. This means with the help of Universal Health Coverage, people are financially protected 
and, as per their need, have access to quality care services such as safe, budgeted and decent quality medicines and vaccines. Apart from making health services available to all economically, Universal Health Coverage is considered as an investment in human capital and serves as an economic growth driver. The UHC is largely dependent on two parameters; one is the coverage of necessary health care services and the other is the amount (in terms of percentage of household income) a country's population spends on health care services. Both parameters take into account the proportion of the population who does not have access to health care and experience financial difficulties due to health care expenditures. Households suffer from financial hardships because of the out-of-pocket expenditures (that are not covered by any third-party insurance) that account for a greater share of household income. These out-of-pocket expenditures expose households to financial risk because health care spending exceeds their ability to afford. As a result of this, people tend to spend more on health care as per their needs and less on necessities such as food, shelter and clothing.

Sometimes, out-of-pocket health expenditures become so heavy that spending on basic needs falls below the threshold value indicated on poverty line. As per the statistics, it is recorded that in 2010, about 800 million people made payments on health care that exceeded $10 \%$ of their household income and around 180 million incurred out-of-pocket health expenditures which exceeded 25\% of their household income share (World Health Organization and International Bank for Reconstruction, 2017). Universal Health Coverage means that irrespective of demographics, income and living standards, every person can seek health care services as per their requirement and the usage of medical services does not create any financial difficulties. It makes it possible for the people in need of medical treatments such that they are still able to afford basic necessities and do not push their families into the risk of poverty at the cost of receiving care. Organizations are 
targeting to make Universal Health Coverage accessible to all economies so that a greater proportion of the population is covered, especially the impoverished. This is because the poor segment of the population is the one who does not receive the desired services as and when needed. According to the agenda of UHC, everyone should have access to quality care so that people are diagnosed and treated correctly for their ailments. Most importantly, Universal Health Coverage does not mean that medical care is free of cost; it merely cuts down the out-of-pocket expenses and reduces financial hardship so that populations are not devoid of seeking care.

\subsection{Role of Employment}

Several outcomes of population health depend on employment. This is because employment is a source of financial security, social status and personal development and promotes physical well being (Marmot et al., 2008). As the basic requirements for healthy and quality living, include shelter (housing), food, clean water and sanitation. Majority of the population relies on employment to meet their basic necessities for healthy living (Linn et al., 1985). The quality of life is mostly dependent on social and economic conditions. Filthy housing conditions, high unemployment and limited access to essential services lead to poor health (Wilkinson and Marmot, 2003). WHO provided evidence from several countries that unemployed people are at a greater risk of premature deaths. Ross and Mirowsky (1995) suggested that there exists a positive correlation between employment and health. People who are employed can support good living conditions and better health (Goodman, 2015). This is because employment boosts the income of the household and provides economic support. A study by Ross and Wu (1995) also reported similar findings on the association between employment and health. They explained that the health and well-being of both men and women improves with the help of employment and unemployment leads to poor health conditions. Work provides access to nutritious food, better health care and a 
healthy and secure housing environment. Accessibility and affordability of these conditions can be attributed to the financial stability provided by employment.

\subsection{Value Chain Breadth and Health}

Value chains comprise a range of activities, from the extraction of raw materials to delivery of the final product to the consumers. It also involves the safe disposal of the used products. A good example is of Starbucks value chain. Starbucks began the journey by testing a variety of coffees from all over the world, such as Latin America, Africa, Arabia, Asia and the Pacific. They developed bonds with the coffee growers and built partnerships to ensure the best quality coffee

to the customers. Another part of the value chain worked on marketing, innovation and development. The marketing, sales, and service teams work on customer satisfaction and introduction of new drinks. Therefore, the Starbucks value chain functions from farms to farmers (coffee growers) to the customers. Each step of the value chain determines the quality of the coffee. Besides this, the Starbucks value chain boosted the economic profitability of the farmers by providing them the opportunity to re-invest in coffee production. In addition, Starbucks created opportunities for tea and coffee growing societies to increase their income. They helped communities by generating employment and providing education and training. For instance, they offered free online bachelor's degree programs to educate their community. They set targets for hiring new graduates, refugees and veterans. Also, they eliminated barriers to employment for partners (Daily, 2019). Therefore, the Starbucks value chain developed the community socioeconomically and provided employment opportunities.

According to Farole et al. (2018), value chains can be the point of focus for generating employment, increasing productivity and skill development. Value chain analysis focuses on the domestic supply chains and facilitates job creation in domestic supply chains. This creates new 
opportunities for the workforce. Generally, in high-income countries or countries with ample resources, job growth is skewed towards high-skilled work. This leads to an increase in inequality as low-skilled jobs are not favored anymore because of technological advancement. Technology overpowers the low-skilled work, which requires limited or no knowledge and skill. Hence, resource-rich countries experience limited or skewed job growth, which has a minimal effect on poverty reduction and a high impact on inequality. According to statistics, 600 million jobs are required over the next ten years to employ the working-age population (Farole et al., 2018).

Value chains carry the potential to facilitate the large-scale creation of jobs that vary from jobs demanding the high-skilled workforce to sustainable opportunities for employment of low-skilled workers. The linkage between high-skilled and low-skilled jobs leads to an increase in global competitiveness and growth in productivity. This is because value chains provide opportunities to large-scale firms, self-employed workers and low-scale firms to expand and develop.

A good example is of Finland and Nokia. Although, Finland is a developed nation but the example dates to 1865 . Finland had a weak economy and lacked capital for investment. Finland was considered the poorest of the four Nordic nations. The Finnish economy faced a lack of financial capital for innovation, which made the development of new products difficult. The economy had a high dependency on its natural qualities, mainly forestry and heavy metal industry. These two industries were responsible for exports. But unfortunately, the volume of exports was not enough for the industry to expand domestically. This was primarily because of two reasons: (1) the absence of advanced technology, and (2) the economic demand for the products. Finland faced the absence of resources for industrial production due to a weak economy and a lack of financial capital. Finland's industry performed poorly due to overreliance on the soviet trade and financial sector (Ainamo, 1997). 
Ainamo (1997) reported that with the decline in the financial market and recession, unemployment increased from 5 to $20 \%$. The incident of Nokia developing Finland dates to 1865 when a wood processing firm was established. This firm was taken over by the Finnish Rubber Works in 1918 and later in 1966, it merged with the telecommunication firm known as Finnish Cable Works. This was called Nokia. Nokia grew to become the second-largest manufacturer of electronics in Finland. Nokia began manufacturing telecommunication devices and electronics along with providing services. Therefore, Nokia's value chain began with processing wood to manufacturing electronics and providing services. Nokia started the manufacture of small microcomputers and automated systems for the pulp and paper industry in 1972. It slowly became a mass producer of electronics. Slowly, Nokia expanded its business into the manufacturing of plastics, metals and chemicals. Nokia developed a strategy that differentiated it from other private firms, and it became the largest privately-owned firm. Electronics and telecommunications became the most profitable industry in Finland.

According to Ainamo (1997), Nokia Corporation twisted the Finnish industrial sector. It not only influenced the Finnish industry but also opened pathways for technology, innovation and economic profitability. Nokia established during the 1980s and became a giant producer of electronics. It invested in related sectors to develop globally. It dominated the Finnish industrial sector. In order to penetrate the industry, Nokia developed close relationships with the partners and key actors. Cooperation with other Finnish firms was the major driver for the growth of the electronic industry of Finland. The economy of Finland slowly and constantly developed with the emergence of Nokia Corporation. Investment in telecommunication infrastructure helped Finland grow to the OECD level. The rising demand for mobile technology from the global market made Finland a global nation leading in mobile communication. Finland tackled the recession with the help of Nokia and 
its strategies in the telecommunication industry. Therefore, Nokia helped the Finnish economy grow and flourish.

Value chain dynamics can result in investment and intervention in the creation of employment. Eventually, value chains can enhance the growth of firms, increase the productivity of jobs, create employment opportunities for marginalized population and improves quality of life. Each step of the value chain adds value to the product or service. As value chains involve a set of activities such as transport and logistics, research, training and finance, change in the dynamics of the core value chain impacts employment for all other activities.

A pilot case study was carried out by Farole et al. (2018) on the potato value chain in Lebanon using surveys and conducting semi-structured interviews of every actor of the chain. This involved suppliers, farmers, traders and processors. The results revealed that there exists a demand for jobs in all dimensions of the value chain. But the demand is for low-skilled labor. Also, in the supplier and processing dimension of the potato value chain, more than $40 \%$ of the females were employed in low-skilled positions and about $80 \%$ of the jobs were managed by the youth in trading and distribution part of the value chain. A study on the Zambia poultry value chain revealed similar findings (Farole et al., 2018). The chain is divided into traditional and modern production sector. The findings differentiate between the qualities of jobs. It states that traditional production has more jobs compared to modern poultry production but the jobs in modern poultry production models have a higher income. This is because modern production requires skillset and education, which improves the productivity of labor.

On the contrary, it is also justifiable that, firms could also expand capital intensively by investing in labor-saving technologies and not hiring people (Farole et al., 2018). The adaptation of technological advancements by firms to grow has affected the demand for labor drastically. For 
example, the manufacturing sector has been investing in labor-saving technologies such as switching to robots, which has substituted labor. This is evident from a study by Fang and Yang (2013) that discussed the impact on the Chinese economy by transforming from labor-intensive sectors to capital and technology-intensive sectors. The author focussed on the manufacturing firms and suggested that with an upgradation of the economy, manufacturing firms are expected to move up the value chain. Another example could be of agribusiness value chain comprising of suppliers, farming, processing, logistics, and distribution, which has low absorption of labor due to capital-intensive activities such as fully mechanized production through investments in laborsaving machines.

Deininger and Byerlee (2011) explained the dynamics of a firm in Brazil in the agribusiness value chain. The firm expanded by developing a new production chain through investments in research and development. The technological intervention made it possible for the firm to produce profits through an increase in production from the land, which was considered unsuitable for agriculture. However, the result of the expansion of the firm into a new product line suggested that it did not contribute to poverty reduction in rural counterparts of the country. This is because the capital subsidies led to a highly mechanized production, which resulted in labor substitution. The results are contrary to the labor-intensive production, where production could create employment.

Although improvements in health contribute to economic growth, capturing economic growth is not in the scope of the study. Economic growth is commonly measured in terms of gross domestic product (GDP) per capita (De Gregorio, 1992; Barro, 2001; Henderson et al., 2012). There exists a strong evidence that better health results in rapid growth of GDP per capita. According to Bloom et al. (2004), health of the population is considered as one of the most important drivers of economic growth. For instance, an increase in life expectancy by one-year results in an increase in 
GDP per capita by 4 percent. Similarly, in East Asian countries health status of individuals improved as a result of decline in mortality and fertility rates and increase in life expectancy from 39 to 67 years. As a result of improved health status, GDP per capita grew rapidly. This is because better health is attributed to an increase in ratio of working-age people (15-64 years) to the dependent people (0-14 and 65 plus years). This resulted in higher worker input per capita and higher GDP per capita.

As discussed above and according to other works in the literature (e.g., see, Bhargava et al., 2001; Howitt, 2005; Well, 2007), better health results in higher economic growth. However, since the scope of our study is to investigate the impact of value chains on population health, we do not consider the impact of further improvement in population health on economic growth. Moreover, inclusion of GDP per capita into the model would result in endogeneity. Endogeneity occurs when dependent variables can cause independent variables (Roberts and Whited, 2013). As per the discussion above, our dependent variables (health) can cause GDP per capita. Therefore, GDP per capita was not included in the model. Endogeneity arises when standard errors are correlated with explanatory variables.

\subsection{Contributions}

To better illustrate the novelty of our current research, we have summarized the previously discussed studies in Table 1.

Table 1. Socio-economic determinants of health

\begin{tabular}{|c|c|c|c|}
\hline Authors (Year) & $\begin{array}{c}\text { Independent } \\
\text { Variable }\end{array}$ & Population Health & Method \\
\hline Leigh (1983) & education & self-reported health & $\begin{array}{c}\text { linear regression and } \\
\text { scatterplots }\end{array}$ \\
\hline Ross and Mirowsky (1995) & employment & sampled households & $\begin{array}{c}\text { ordinary least squares and } \\
\text { logistic regression }\end{array}$ \\
\hline Ross and Wu (1995) & employment & self-reported health & multiple regression analysis \\
\hline
\end{tabular}




\begin{tabular}{|c|c|c|c|}
\hline Leipziger et al. (2003) & infrastructure & $\begin{array}{c}\text { child mortality rate, } \\
\text { infant mortality rate, } \\
\text { malnutrition rate } \\
\end{array}$ & $\begin{array}{l}\text { seemingly unrelated } \\
\text { regressions }\end{array}$ \\
\hline $\begin{array}{l}\text { Wilkinson and Marmot } \\
\text { (2003) }\end{array}$ & employment & $\begin{array}{c}\text { self-reported ill } \\
\text { health, premature } \\
\text { deaths }\end{array}$ & theoretical \\
\hline Shandra et al. (2004) & education & infant mortality rate & lagged panel regression \\
\hline $\begin{array}{l}\text { Levine and Rothman } \\
\text { (2006) }\end{array}$ & trade tariffs & $\begin{array}{l}\text { child mortality rate, } \\
\text { infant mortality rate, } \\
\text { life expectancy }\end{array}$ & $\begin{array}{l}\text { two-stage least squares } \\
\text { regression }\end{array}$ \\
\hline Smith (2006) & trade tariffs & mortality rate & theoretical \\
\hline World Bank (2007) & education & $\begin{array}{l}\text { adolescent birth rate, } \\
\text { maternal mortality } \\
\text { rate }\end{array}$ & bar graphs and scatterplots \\
\hline Dash and Sahoo (2010) & infrastructure & infant mortality rate & $\begin{array}{c}\text { two-stage least squares } \\
\text { (TSLS) and dynamic ordinary } \\
\text { least squares (DOLS) }\end{array}$ \\
\hline $\begin{array}{l}\text { Mingat and Majgaard } \\
(2012)\end{array}$ & education & maternal mortality & $\begin{array}{c}\text { linear regression, logit } \\
\text { regression and scatterplots }\end{array}$ \\
\hline Pierce \& Schott (2016) & trade tariffs & mortality Rate & $\begin{array}{l}\text { ordinary least squares and } \\
\text { two-stage least squares }\end{array}$ \\
\hline Ha et al. (2019) & inflation & $\begin{array}{l}\text { malnutrition, } \\
\text { maternal mortality } \\
\text { ratio }\end{array}$ & bivariate regressions \\
\hline
\end{tabular}

Several researchers focus on socio-economic determinants of health such as infrastructure, trade tariffs, inflation and education. The study on infrastructure by Calderón and Servén (2004) and Snieška and Šimkūnaitė (2009) discussed the role of infrastructure in improving the health of the public. With an improvement in the quality of infrastructure, people in the developing nations have higher access to resources that impacts their quality of life, education and income. Calderón and Servén (2004) determined the impact of the quality of infrastructure on economic growth. Snieška and Šimkūnaitè (2009) also concluded that infrastructure positively impacts health and education outcomes and good health and education induces economic growth. 
It is believed that health status of the population is not entirely dependent on the health systems especially for developing nations, instead, nutrition, accessibility to clean water and sanitation, education and income determine population health (Blouin et al., 2005). Liberalization of trade and reduction in trade tariffs facilitates supply of resources across the borders. According to Pierce and Schott (2016), reduction in trade tariffs is followed by the reduction in prices of commodities and rise in real income of the public.

The study by The World Bank (2019) on inflation reflects on the disproportionate effect of inflation on poor households. The rise in inflation influences the food security of the population, i.e., a sudden rise in commodity prices would result in the population spending less on food due to a reduction in purchasing power giving rise to malnutrition and decline in health status (The World Bank, 2019). Additionally, basic education improves access to better food and nutrition, which affects the population health (Leigh, 1983).

One of the contributions of our research is to combine all the possible factors in one model to explain the population health. To the best of our knowledge, previous studies covering the social and economic determinants of health did not control for Universal Health Coverage (UHC). This has been also indicated by Chapman, 2019. However, it has been an important concern for World Development Organizations to achieve UHC by 2030. Based on the availability of certain measures that govern the formation of the Universal Health Coverage index, the index measure is available only for the year 2015 (World Health Organization and International Bank for Reconstruction, 2017). Since the goal of UHC is to provide affordable health care services to the public with a wide range of income levels, the impact of each of the determinants of population health might differ when controlled for UHC. Our study contributes to the literature by studying the impact of different socio-economic determinants on population health while controlling for 
Universal Health Coverage. Our work describes that, with the inclusion of Universal Health Coverage, what role infrastructure, inflation, education and trade play in determining the health status of the population. Previous research focused on the role of income in enhancing population health. This is because the important predictors of a healthy life are the accessibility to basic necessities such as food, shelter, water and sanitation and clothing (Blouin et al., 2005). Poor health is attributed to high unemployment, poor living conditions and minimal access to basic facilities (Wilkinson and Marmot, 2003)

Our study introduces the concept of the value chain and what role value chains play in improving the health of the population. Value chains involve firms that participate in different levels of the chain. The expansion of the firm could be labor intensive or capital intensive. Firms investing in labor-intensive sectors grow to generate employment, which raises the economic productivity of the workforce. However, firms could also expand capital intensively by investing in labor-saving technologies and not hiring people or creating jobs (Farole et al., 2018). Therefore, apart from the socioeconomic predictors of population health and economic growth, this study contributes to the literature by analyzing the impact of the value chain on the health of the population. Value chains, unlike other factors, contribute to the economic growth of the nation (Fang and Yang, 2013). Our study is focussed on investigating the impact value chains might have on population health. 


\section{Chapter 3 \\ Hypothesis Development}

The measures used to describe population health in our study are infant mortality rate, maternal mortality rate, adolescent birth rate and life expectancy at birth (World Health Organization, 2015). Socio-economic factors such as infrastructure, trade, inflation and education impact population health to a large extent. Infrastructural advancement results in economic development. This is primarily because improvement in infrastructure facilitates quality of living and promotes healthy life. Investment in transport, communications and power infrastructure help in the development of human capital (Snieška and Šimkūnaitė, 2009). For example, transport improves transition and accessibility in less developed nations and exposes poor households to economic opportunities. Policies imposing greater tariff rates on the traded goods and services result in poor health status of the population. This is because, for developing nations, health of the individuals does not merely rely on the health systems but on clean and safe water and sanitation, education and income (Blouin et al., 2005). For example, reduction in tariff rates on food imports results in increased accessibility to daily nutritional requirements of the population which leads to better health of the population. Inflation is also a crucial parameter that not only deteriorates the health of the individuals but also hampers their purchasing power. A study reported that uncontrolled inflation reduces the purchasing power of the population (The World Bank, 2019). Individuals tend to reduce their daily intake of nutrition as a result of rising food prices leading to malnutrition and poor health. Education acts as a strong determinant of population health. A study by Ross and Wu (1995) implied that good health is an attribute of years of schooling. This is because better physcial health 
and lower levels of morbidity, mortality and disability are recorded in households with basic level of education.

Apart from the socio-economic factors discussed above, one such factor that might have an impact on population health is value chain breadth. Value chains capture the expansion or growth of businesses or firms. It estimates that if the firms are investing in initial parts of the chain or moving up the chain. For example, a firm investing only in the manufacturing domain has a narrow presence in the value chain as compared to the firms that are heavily investing in distribution, marketing and design apart from manufacturing. A greater presence in the value chain results in better employment opportunities (Farole et al.,2018). Employment serves as medium of financial security. Employed individuals experience a greater level of physical well being (Marmot, et al., 2008). Generally, people rely on employment to satisfy their basic needs such as food, shelter and clothing to support a healthy living (Linn et al., 1985). On the contrary, firms or businesses could also grow capital intensively. Capital intensive expansion requires investing in technological advancements which result in labor substitution. Irrespective of the nature of growth, firms with a broader presence in value chains result in economic development of the country (Ainamo, 1997; Fang and Yang, 2013; Farole et al., 2018). A positive association exists between health and development of economy (Bloom and Canning, 2009). Better health contributes to economic growth. Since population health is measured by four variables, to analyze the potential impact, we develop four hypothesis. The impact is moderated by employment rate. This is because, as firms become competitive by broader presence in the value chain, irrespective of the nature of expansion, we want to explore if the country promotes initiatives to increase labor demand resulting in development of human capital and healthy population. Based on the discussion, following four hypotheses were developed: 
H1: The impact of value chains on infant mortality rate is moderated by employment rate.

$\mathrm{H} 2$ : The impact of the value chains on the maternal mortality rate is moderated by the employment rate

H3: The impact of the value chains on the adolescent birth rate is moderated by employment rate

H4: The impact of the value chains on life expectancy is moderated by employment rate

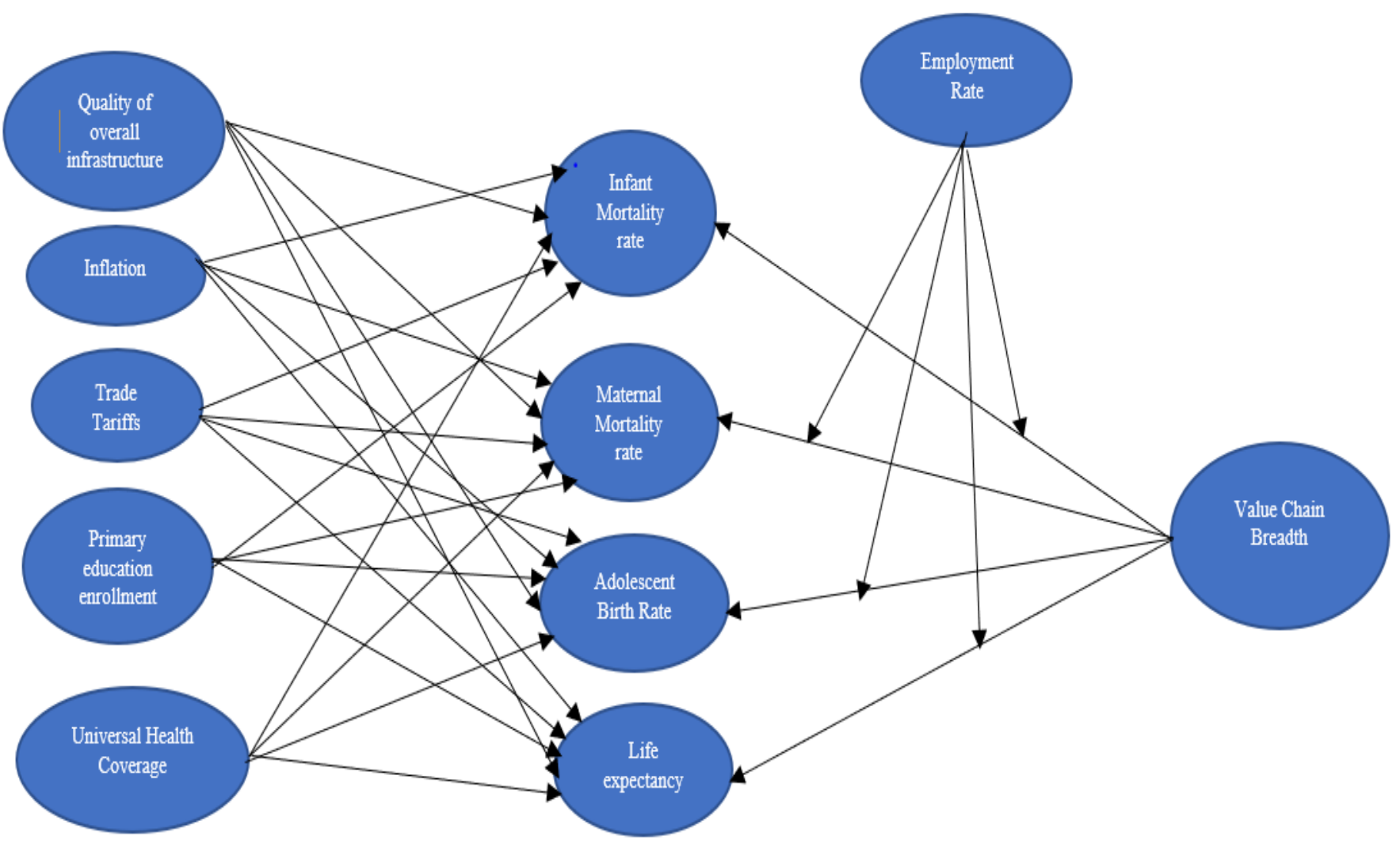

\section{Figure 1. Theoretical Model}

Figure 1 illustrates the factors that might have an impact on population health. The population health outcomes discussed in the literature are infant mortality rate, maternal mortality rate, 
adolescent birth rate, and life expectancy at birth. Our research investigates the potential impact of value chain breadth on population health outcomes. The impact of value chain breadth on population health outcomes is moderated by employment rate. Based on the literature, value chains can be labor or capital intensive. Since the index used in the analysis does not capture the nature of firm expansion, we use employment rate as a moderator to explore if the government or the policy makers consider labor demand initiatives as the firms expand or become competitive. This is important for the development of human capital. 


\section{Chapter 4 \\ Methodology}

This chapter describes the specification of the model, data collection method, description of variables and method of analysis.

\subsection{Specification of the model}

$$
\begin{aligned}
& \text { Population Health }_{i t}=f\left(\text { Infrastructure }_{i t}+\text { Value Chain }_{i t}+\text { Trade }_{i t}+\right. \\
& \text { Inflation } \left._{i t}+\text { Education }_{i t}\right)
\end{aligned}
$$

where, $i=$ number of countries and $t=$ number of years

In the above equation, population health is measured by four variables, namely, infant mortality rate, maternal mortality rate, life expectancy at birth and adolescent birth rate. Infrastructure is captured in terms of quality of overall infrastructure. Value chains are measured in terms of the breadth of the chain. Education is expressed as the primary school enrolment rate and inflation is measured as the annual percentage change in the consumer price index. A more detailed discussion will be provided in this section.

\subsection{Data and Sample}

The secondary cross-sectional time-series data for infant mortality rate, maternal mortality rate, adolescent birth rate, and life expectancy at birth is collected from the World Bank health status indicators for the years 2007-2015 (The World Bank, n.d.) and are used as proxy measures for population health. The data used in the analysis is only for developing nations because of the statistics reported by various health organizations concerning the alarming situation of health and economic development in developing countries. 
Time series data for variables such as quality of overall infrastructure, inflation, primary education enrolment rate, and trade tariffs are collected from the Global Competitiveness reports published for the years 2007-2015. Also, the independent variable used in our study, value chain breadth is also collected from the Global Competitiveness reports (Schwab, 2012). The indicators are recorded and calculated based on the executive opinion survey carried out by the World Bank and partner institutes. Partner institutes that participated in the survey were research and academic institutions, business organizations, Council for National Competitiveness and established professional entities (World Bank, 2017).

Another factor, Universal Health Coverage index, is collected from the World Health Organization reports (World Health Organization and International Bank for Reconstruction, 2017). Based on the availability of data on certain measures required to calculate the coverage index, the index measure is available only for the year 2015. In our study, we are considering the same index value for the years 2007-2015 for developing nations. This is because the calculation of universal health coverage index covers the following health parameters (Hogan et al., 2018):

a. Reproductive, maternal, newborn and child

b. This parameter considers the family planning, immunization and antenatal and child care (seeking a cure for pneumonia)

a. Infectious disease control

b. This factor includes treatment for HIV, tuberculosis and insecticides

c. Basic sanitation

- Non- communicable diseases

a. This covers four factors, namely, screening for cervical cancer, non-usage of tobacco, mean fasting plasma glucose and non-raised blood pressure 
- $\quad$ Service capacity and access

a. This includes crucial medical care facilities such as hospital bed and health worker density, access to medicines and IHR core capacity index

Since there is not a wide variation in the availability of these services (listed above) in most of the developing countries, therefore, there is no significant change in the Universal Health Coverage index recorded by the World Health Organization. Therefore, it is fair to assume that the index value does not change quickly from year to year for a specific country. Furthermore, the timeseries data for the moderating variable, that is, the employment rate, is retrieved from the International Labour Organization database published by the World Bank (The World Bank|data, n.d.).

\subsection{Variable Description}

A detailed description of the variables is presented below.

\subsubsection{Dependent Variables}

Our first measure of population health is the infant mortality rate. About 2.7 million infants died in the year 2015 globally within the first 28 days of birth, with $73 \%$ of the deaths occurring in the

first week of birth (World Health Organization, 2015). Several studies measure infant mortality rate as a measure of the health of the population (Navarro et al., 2006; Government of Canada, 2008; New Jersey Department of Health, 2019). The infant mortality rate is defined as the probability of infants born in a year dying before the age of one per 1000 live births (World Health Organization, WHO statistical information system, 2016).

The second measure used as a proxy for population health is the maternal mortality ratio (World Health Organization, 2015). It is recorded as the number of maternal deaths during a given time period per 100,000 live births during the same time frame (WHO, UNICEF, UNFPA, World Bank 
Group, \& United Nations Population Division, 2019). About 500,000 pregnant mothers die every year in developing countries (World Bank, 2007).

As per the statistics, the world experienced a decline in the maternal mortality ratio from 342 maternal deaths per 100,000 live births in 2000 to 211 in 2017 (World Bank Blogs, n.d.). It has also been recorded that complications during pregnancy and childbirth claimed the lives of 295,000 women globally in the year 2017. The highest number of deaths were recorded in SubSaharan Africa at 534 deaths per 100,000 live births. South-Asia holds the second position at 163 deaths per 100,000 live births.

The third dependent variable used as a representation of population health is the adolescent birth rate (World Health Organization, 2015). The fertility rate is defined as the number of live births to women age 15-19 years divided by an estimate of exposure to childbearing by women of the same age group (World Health Organization, 2013). The adolescent birth rate is 44 per 1000 girls aged 15-19 years (World Health Organization, 2016).

The final proxy measure used for population health is life expectancy at birth (Judge, 1995; De Vogli et al., 2005; Government of Canada, 2016). The overall mortality rate of the population is explained by life expectancy at birth. Life expectancy is measured as the average number of years a newborn is expected to live irrespective of the current mortality rates (World Health Organization, WHO statistical information system, 2016). It is an important measure of population health because, since 1960, there has not been any remarkable increase in the average life expectancy at birth except from the one recorded from 2000 to 2016, where it increased by 5.5 years globally (World Health Organization, n.d.). 


\subsubsection{Independent variables}

The independent variables used in the study are discussed below.

a. Quality of Overall Infrastructure: This indicator captures the quality of infrastructure of a country. It is a weighted average of the state of infrastructure in the country. It is an index specified in the Global Competitiveness report measured on the scale of 1 to 7.1 being extremely poor or underdeveloped and 7 meaning extremely efficient. The infrastructure components covered in the index include transport, communications, water and sanitation, and power or energy. Infrastructure impacts the population health and economic growth (Calderón and Servén, 2004; Agénor and Moreno-Dodson, 2006; Snieška and Šimkūnaitè, 2009). Calderón and Servén, (2004), defined quality of public infrastructure as a combination of telecommunications, power and transport. In our study, we use the index developed by world bank capturing all the components of infrastructure.

b. Inflation: It is measured as the percentage change in the consumer price index. It is averaged over one year. This is measured because the rise in inflation influences the food security of the population, that is, a sudden rise in commodity prices would result in the population spending less on food due to reduction in purchasing power giving rise to malnutrition and decline in health status (The World Bank, 2019).

c. Trade Tariffs: It is used as a proxy measure for trade liberalization. It is measured as the duty applied to imported goods. It is calculated as an average of all the applicable tariff rates. Therefore, it is the weighted average of all the tariff rates. According to Blouin et al. (2005), the accessibility to the basic necessities (nutrition, accessibility to safe and clean water and sanitation, education and income) could be improved by liberalizing the trade 
and reducing tariff rates to ease the supply of resources across borders. Reduction in tariff rates leads to a drop-in commodity prices and the rise in the real income of the public.

d. Primary Education Enrolment Rate: This is used as a proxy measure for education. It is measured as the ratio of children who are of the primary school age as specified by the national education system with respect to students who are enrolled in school. This is an important measure because education helps increase the awareness of food, nutrition and water and sanitation (which are the root cause of deteriorating health status of the populations) among the people. Basic education improves access to better food and nutrition, which impacts the health of the public (Leigh, 1983).

e. Universal Health Coverage: It is measured on a scale of 0-100. The index is calculated as an aggregate measure of 16 health indicators, including reproductive, maternal, newborn and child, infectious disease control, non-communicable diseases and health care services such as hospital bed density (World Health Organization and International Bank for Reconstruction, 2017). Universal Health Coverage improves access to basic care facilities at affordable prices so that everyone could access it without any financial hardship. This measure is included in the work to study the impact of socio-economic variants on the health status of the population, even if the nation has health coverage universally available to the public.

f. Value Chain Breadth: It is defined as the width of the companies' value chain in the country. It is measured on a scale of 1 to 7 . If the companies have a narrow chain that is only involved in the initial steps of the value chain, for example, extraction of resources or production, the value chain breadth is 1 . The index is 7 if the companies exhibit a larger presence in the value chain, i.e., the companies are involved not only in production but also 
in marketing, distribution and design (World Bank, 2017). The score is calculated by the World Bank at the country level by multiplying the score of the country in previous year and weight applied to a country's score. The weights are calculated by dividing a country c's sample size in the year $t$ by the sample size of country in the year $t$ and $t-1$ (World Bank, 2017). These equations are included in the appendix.

g. Employment Rate (moderator): It is captured as people employed in industry as a percentage of total employment. It is captured as the weighted average of people of working age who are employed in activities to produce goods or to provide services where they are paid irrespective of whether at work or not at work due to temporary absence from the work. Employment improves the affordability of the public. It improves the purchasing power of the public to access basic resources such as food, water and sanitation. Moreover, people can have better access to primary care, such as vaccines. As firms grow their businesses or move up the value chain, they may expand in labor intensive sectors or capital-intensive sectors. The information we have on value chain breadth was not categorized based on labor- or capital-intensive sectors. When firms expand capital intensively, they do not invest in hiring people (Farole et al., 2018). Whereas, labor intensive expansion generates employment. Therefore, the impact of value chain breadth on population health is not entirely mediated by employment rate based on the nature of expansion of the firm.

We are focusing on the population health outcomes, which have achieved worldwide attention. Through this study, we investigate that as the firms become competitive due to the broader value chain, how they impact the human development factors, i.e., population health. The purpose of choosing the employment rate as a moderator is because we want 
to explore that as the firms grow, does the government enforce employment or labor demand initiatives for development of human capital and to promote quality of living.

\subsection{Method}

The data set comprised of 88 developing nations as specified by the United Nations (The United Nations, n.d.). It is a cross-country panel data set spanning over 8 years (2007-2015). There are several models that are used widely to analyze panel data. Panel data is a combination of time series and cross-sectional data. One of the main advantages of panel data is that dynamics of change with short time series could be studied. As panel data has two dimensions (i.e., space and time), it improves the quantity and quality of data (Gujarati, 2003). The spatial dimension of panel data involves cross-sectional observations, for example, countries, firms, commodities and so on. The time dimension of panel data includes observations of a set of variables relating to these cross-sectional units over a certain time period. The type of models used in several types of research involving panel data analysis is constant coefficient, fixed effects, random effects and feasible generalized least square model (Yaffee, 2003). Each of these methods is briefly described below.

\section{Constant coefficient model}

In this type of model, ordinary least squares regression is performed on the whole data set. This model considers the same slope and intercept for the whole data set and does not take into account country or temporal effects. This model is also called the pooled regression model.

\section{Fixed Effects model}

The second type of model used for panel data analysis is the one with constant slope but different intercepts. The fixed effects estimators are also known as within group estimators 
because they rely on the deviations from their group means. Intercepts change with respect to the cross-sectional units such as countries. Since there is a significant difference between the countries, the intercept differs from country to country, but it may or may not differ with respect to time. One of the drawbacks of the fixed effects model is that they frequently have too many observations for cross-sectional units, which further gives rise to multicollinearity (Yaffee, 2003). Multicollinearity can elevate the standard errors, which may lead to incorrect significance of parameters. The model assumes that residuals are normally distributed and homogenous, but there could be country-specific heteroscedasticity or autocorrelation over time.

\section{Random Effects Model}

This model endows regression with a random constant term and random intercept. The intercept is assumed to be a random outcome variable, which is the sum of mean value and random error. This model assumes that random errors are specific to a cross-sectional observation such as country and are constant over time. The model assumes that the error terms must be uncorrelated with both time and country components. In the case of panel data used in our study, there is a wide variation across cross-sections (countries) and time. This model neither assumes heteroskedasticity nor autocorrelation between panels.

\section{Feasible Generalized Least Squares (FGLS)}

Since there is a huge variation across cross-sections and over the time period, the data is heterogeneous and autocorrelated. To account for heteroskedasticity and autocorrelation, estimated or feasible generalized least square models are used. Yaffee, 2003; Liu et al., 2016; Vu et al., 2008 suggested that in case of a large sample size if autocorrelation inflates the standard errors, Feasible Generalized Least Squares can be used. 
We performed a feasible generalized least-squares (FGLS) analysis to get the desired results. The standard errors are not biased, and the significance of variables is not altered. This can be explained by the cross-sectional time-series study done by Johnstone and Labonne (2004) on a group of countries. The author described feasible generalized least squares as a favorable method because it allows for the estimation of panel data in which standard errors are heteroskedastic and serially correlated. In another researcher study, Padovano and Galli (2001) performed empirical analysis to investigate the impact of tax rates on the economic growth of the country using feasible generalized least squares regression to account for serial correlation and heteroskedasticity in a cross-country panel data set. In a more recent study, Vu et al. (2008) described FGLS as the best approach in the case of cross-sectional panel data set. The data comprised of FDI inflows from eight different sectors of Vietnam from 1990-2003 and five different sectors of China from 19972004. The authors justified that when the relationship between FDI and GDP interacts with labor, heteroskedasticity takes place and hence, FGLS is the best approach to analyze the impact.

The independent variables such as quality of overall infrastructure and value chain breadth are collected from the World Bank. The collection of data was based on the surveys and interviews; therefore, the type of data is ordinal. However, even for ordinal independent variables, feasible generalized least squares (FGLS) is the appropriate method. This can be indicated by several studies (Nielson, 2003; Heisig, 2011; Philippe and Durand, 2011; Kollmeyer and Pichler, 2013). Heisig (2011) analyzed the relationship between household income and housework time. The data set comprised of 33 countries. Some of the independent variables comprised of ordinal data collected from the household survey responses on a 7-point scale. The author performed ordinary least square (OLS) regression which resulted in homoskedasticity and biased standard errors. To address these issues, the author performed FGLS regression for the desired results. Another study 
conducted by Philippe and Durand (2011) consisted of a panel data set comprising of 90 firms. The data spanned over 3 consecutive years from 2001-2004. The study aimed to find a relationship between environmental disclosure and firm's reputation. The authors used ordinal measures of firms' environmental disclosures and the dependent variable comprised of the rank of firm as a measure of firm's reputation. The method of analysis used in this study was feasible generalizedleast squares (FGLS) regression to account for country specific heteroskedasticity and correlated panels. In a more recent study, Kollmeyer and Pichler (2013) conducted country level analysis to analyze the impact of deindustrialization on unemployment rate. The dependent variable comprised of unemployment rate. The independent variables included manufacturing employment rate, environmental protection legislation, wage bargaining, etc., where some independent variables such as wage bargaining consisted of ordinal values. The data set comprised observations of 16 countries between 1970 and 2003. The suitable method for the analysis adoped by the authors was FGLS to account for serial correlation and heteroskedasticity. 


\section{Chapter 5}

\section{Analyses and Results}

As discussed, the secondary cross-sectional time-series data for all the four dependent variables are collected from World Bank health status indicators for the years 2007-2015 (The World Bank,

n.d.). The four health status indicators used in our study are used as proxies for population health. One of the major independent variables used in our study, value chain breadth, is collected from the Global Competitiveness reports (World Bank, 2017). As mentioned previously, the employment rate is used to study the moderating impact of value chain breadth on population health. In our study, we are covering developing nations as specified by the United Nations (The United Nations, n.d.). The correlational and multicollinearity tests are provided in the appendix. The results for all the four dependent variables are presented in the following sub-sections.

\subsection{Impact of the value chain on infant mortality rate}

The panel analysis equation can be presented as:

$$
\begin{aligned}
\text { infm }_{i t}=\propto_{i}+ & \beta_{1} \text { inf }_{i t}+\beta_{2} v c b_{i t}+\beta_{3}(v c b \times e r)_{i t}+\beta_{4} \text { infla }_{i t}+\beta_{5} \text { tarif }_{i t}+\beta_{6} \text { per }_{i t} \\
& +\beta_{7} u h c i_{i t}+\varepsilon
\end{aligned}
$$


Table 2. The impact of value chain on infant mortality rate

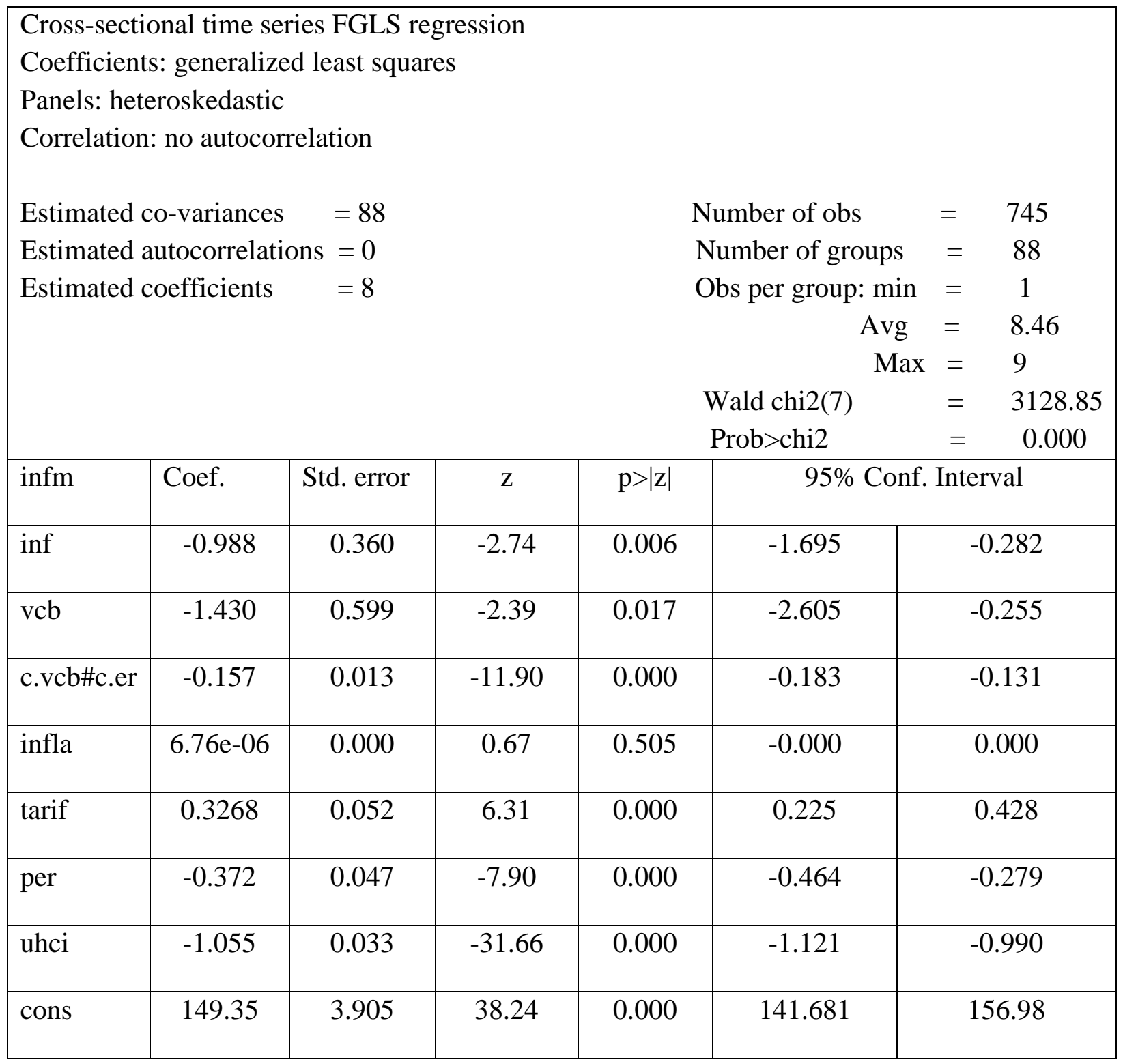

Infm: infant mortality rate, inf: quality of overall infrastructure, vcb: value chain breadth, infla: inflation, er: employment rate, tarif: trade tariffs, per: primary education enrolment rate, uhci: universal health coverage index

The statistical results presented in Table 2 capture 745 observations from 88 developing countries. The probability value of $\mathrm{chi}^{2}$ is less than 0.05 ; this means that the overall model is significant. The results indicate a negative and significant relationship between infrastructure and infant mortality rates. It states that a 1-unit increase in quality of infrastructure results in the decrease in infant 
mortality by 0.98 infant deaths per 1000 live births and the result is significant $(\mathrm{p}<0.05)$. The relationship between trade tariffs and infant mortality is also significant. An increase in tariff rates by $1 \%$ leads to an increase in the infant mortality rate by 0.33 . Inflation is reportedly having no significant impact on the infant mortality rate. Education significantly impacts the population health. As the results illustrates, an increase in the primary education enrolment rate by $1 \%$ results in a decrease in infant mortality rate by 0.37 and this impact is statistically significant. Finally, the universal health coverage index explains that the higher is the access to health care, the lower is the infant mortality rate. The results justify that an increase in the coverage index by 1 leads to a decrease in the infant mortality rate by 1.05 .

Value chain breadth, when moderated by employment rate, results in a decrease in infant mortality rate by 0.16 . Higher value chain breadth results in better health of the individuals and the impact is moderated by the employment rate. Therefore, an increase in value chain breadth by 1 -unit and a corresponding increase in employment rate by $1 \%$ leads to a decrease in infant mortality rate by 0.16 and the results are statistically significant $(\mathrm{p}<0.05)$. The results obtained are intuitive. However, a detailed explanation of the results is provided in the implication section.

\subsection{Impact of the value chain on maternal mortality rate}

The panel analysis equation can be presented as:

$$
\begin{aligned}
m_{i t}=\propto_{i}+ & \beta_{1} \text { inf }_{i t}+\beta_{2} v c b_{i t}+\beta_{3}(v c b \times e r)_{i t}+\beta_{4} i n f l a_{i t}+\beta_{5} \text { tarif }_{i t}+\beta_{6} p_{e r} \\
& +\beta_{7} u h c i_{i t}+\varepsilon
\end{aligned}
$$


Table 3. The impact of value chain on maternal mortality rate

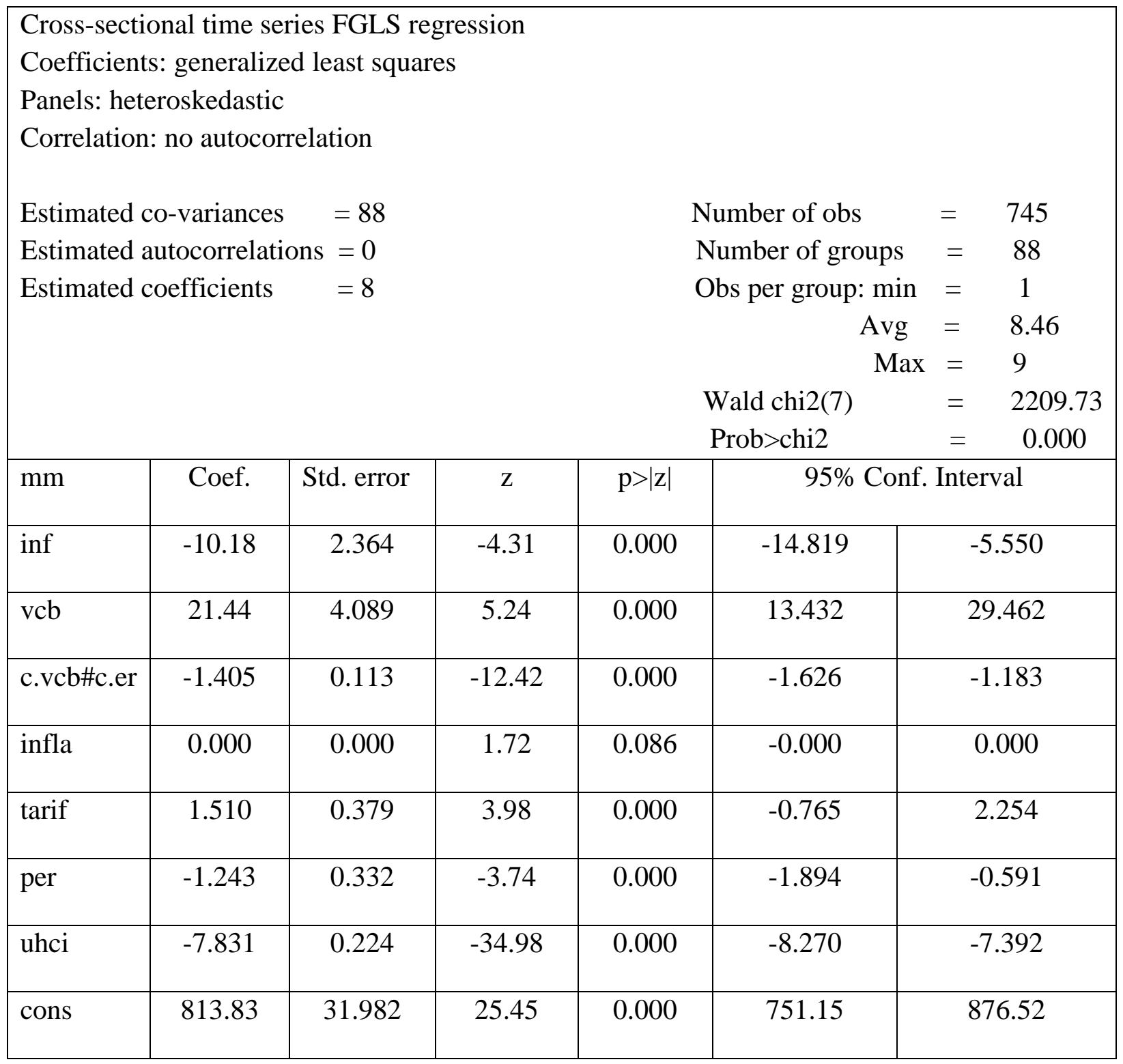

mm: maternal mortality rate, inf: quality of overall infrastructure, vcb: value chain breadth, infla: inflation, er: employment rate, tarif: trade tariffs, per: primary education enrolment rate, uhci: universal health coverage index

The statistical results presented in Table 3 indicate a negative and significant relationship between infrastructure and maternal mortality rates. It states that a 1-unit increase in quality of infrastructure results in the decrease in maternal mortality ratio by 10.2 and the result is significant $(\mathrm{p}<0.05)$. The relationship between trade tariffs and maternal mortality ratio is also significant. An increase 
in tariff rates by $1 \%$ leads to an increase in the maternal mortality ratio by 1.5 . Inflation is reportedly having no significant impact on maternal mortality ratio $(\mathrm{p}=0.086)$. Education significantly impacts the population health. As the results state, an increase in the primary education enrolment rate by $1 \%$ results in a decrease in maternal mortality ratio by 1.24 and the coefficient is statistically significant. Finally, the universal health coverage index explains that better is the access to health care, lower is the maternal mortality ratio. The results justify that an increase in the coverage index by 1 lead to a decrease in the maternal mortality ratio by 7.8 .

An increase in value chain breadth by 1 unit and a corresponding increase in employment rate by $1 \%$ leads to a significant decrease in the number of women dying during pregnancy per 100,000 live births by 1.4. Employment/job or work is a source of financial security, social status and personal development and promotes physical well being (Marmot et al., 2008). Employment makes food, nutrition, water and other basic facilities accessible to the people, especially the poor and disadvantaged. Therefore, higher accessibility to basic necessities boosts maternal health and improves the well-being of the individual. The results obtained are intuitive. However, a detailed explanation of the results is provided in the implication section.

\subsection{Impact of the value chain on the adolescent birth rate}

The panel analysis equation is presented below.

$$
\begin{gathered}
a b r_{i t}=\propto_{i}+\beta_{1} i n f_{i t}+\beta_{2} v c b_{i t}+\beta_{3}(v c b \times e r)_{i t}+\beta_{4} i n f l a_{i t}+\beta_{5} \text { tarif }_{i t}+\beta_{6} \text { per }_{i t} \\
+\beta_{7} u h c i_{i t}+\varepsilon
\end{gathered}
$$


Table 4. The impact of value chain on adolescent birth rate

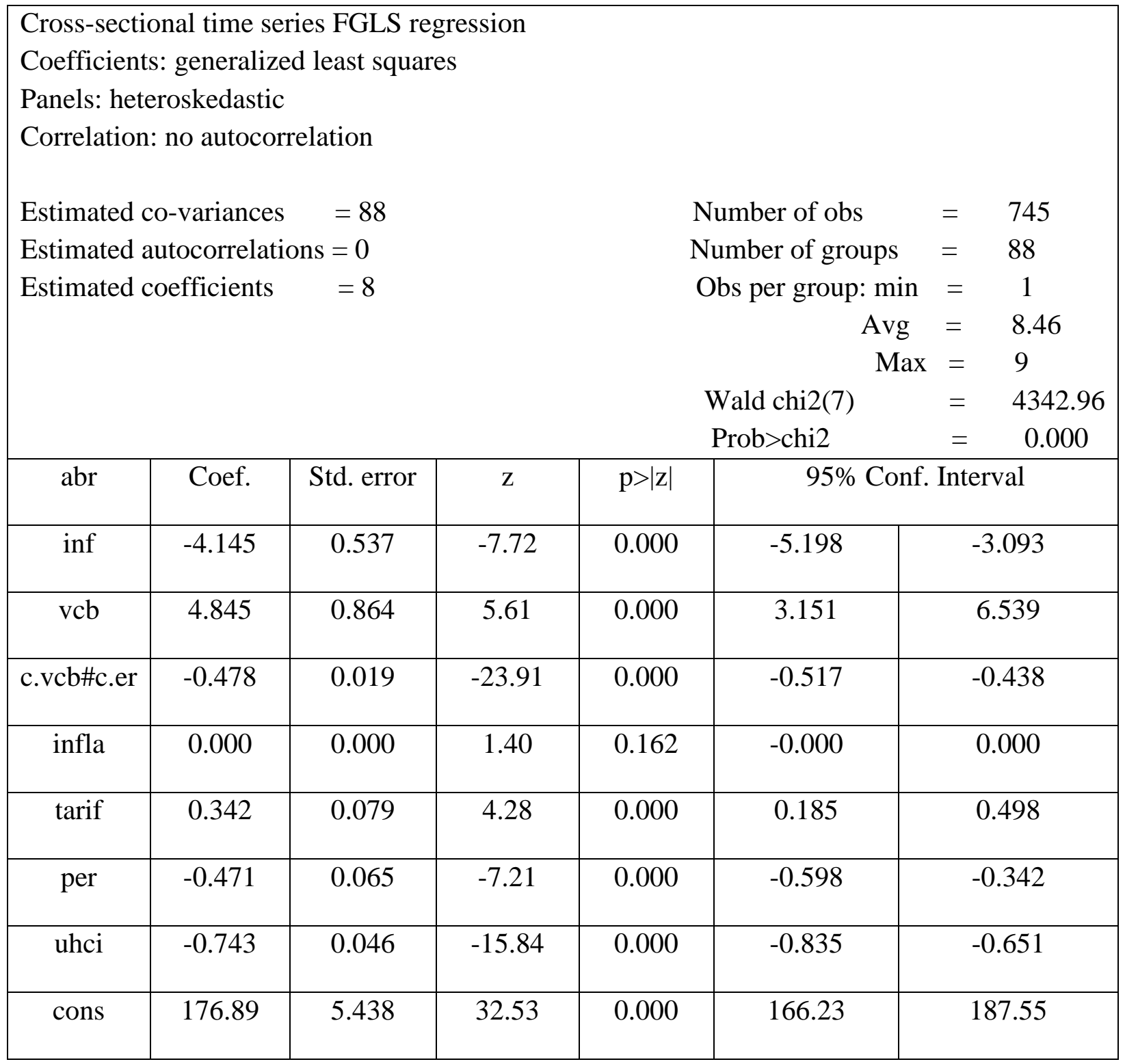

abr: adolescent birth rate, inf: quality of overall infrastructure, vcb: value chain breadth, infla: inflation, er: employment rate, tarif: trade tariffs, per: primary education enrolment rate, uhci: universal health coverage index

Table 4 presents findings of time-series panel regression of 88 developing nations on the relationship between the dependent variable (adolescent birth rate) and independent factors. The socio-economic factor, infrastructure has a significant impact on the adolescent birth rate. The negative sign of the coefficient indicates that an increase in infrastructure quality by 1 unit leads 
to a decrease in adolescent birth rate by 4.1 per 1000 girls aged $15-19$ years. Also, a very small pvalue $(<0.001)$ indicates that the relationship is statistically significant. On the contrary, trade tariffs impact this parameter of population health negatively. The results state that an increase in tariffs by $1 \%$ results in an increase in adolescent birth rate by 0.44 per 1000 girls aged $15-19$ years and the impact is statistically significant. As reported for the other two parameters used as proxies for population health, inflation has no significant impact on the adolescent birth rate. The adolescent birth rate is reported to decrease by 0.47 per 1000 girls aged 15-19 years with an increase in primary education enrolment rate by $1 \%$. Universal Health coverage impacts the health of individuals significantly. An increase in index value by 1 result in a decrease in the adolescent birth rate by 0.74 per 1000 girls aged $15-19$ years.

Value chain breadth, when moderated by employment rate, results in a decrease in adolescent birth rate by 0.488 . Higher value chain breadth results in better health of the individuals and the impact are moderated by employment. Therefore, an increase in value chain breadth by 1 unit and a corresponding increase in employment rate by $1 \%$ leads to a statistically significant decrease in adolescent birth rate by 0.5 .

\subsection{Impact of the value chain on life expectancy}

The panel analysis equation is formulated below.

$$
\begin{gathered}
\text { le }_{i t}=\propto_{i}+\beta_{1} i n f_{i t}+\beta_{2} v c b_{i t}+\beta_{3}(v c b \times e r)_{i t}+\beta_{4} \text { infla }_{i t}+\beta_{5} \text { tarif }_{i t}+\beta_{6} \text { per }_{i t} \\
+\beta_{7} u h c i_{i t}+\varepsilon
\end{gathered}
$$


Table 5. The impact of value chain on life expectancy at birth

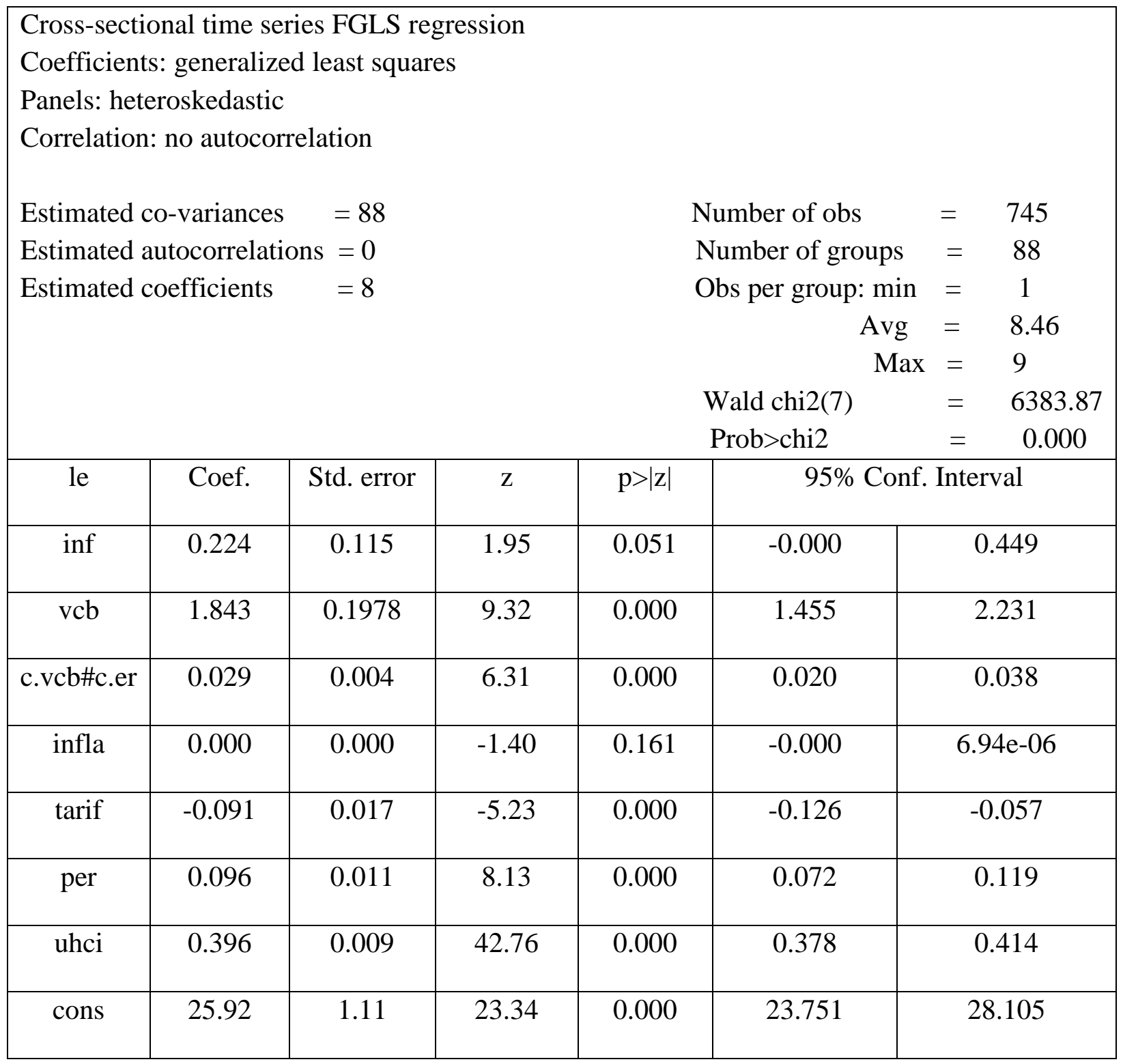

le: life expectancy at birth, inf: quality of overall infrastructure, vcb: value chain breadth, infla: inflation, er: employment rate, tarif: trade tariffs, per: primary education enrolment rate, uhci: universal health coverage index

Contrary to the infant and maternal mortality rates and adolescent fertility rate, life expectancy is expected to show inverse relationship with the independent variables. The statistical results in Table 5 show that an increase in quality of infrastructure by 1 unit significantly increases the life expectancy by 0.22 year. Tariff increases at $1 \%$ leads to a decrease in life expectancy by 0.09 year. 
Similarly, education measured by the primary education enrolment rate positively and significantly impacts the population health. The results report that a $1 \%$ increase in enrolment rate improves life expectancy at birth by 0.096 year and the coefficient is statistically significant. Finally, the statistical results report that when the universal health coverage index rises by 1 , it improves the life expectancy by 0.4 year.

Value chain breadth, when moderated by employment rate, results in an increase in life expectancy by 0.03 year. Higher value chain breadth results in a higher quality of living and the impact is moderated by employment. Therefore, an increase in value chain breadth by 1 unit and a corresponding increase in employment rate by $1 \%$ leads to a statistically significant increase in life expectancy by 0.03 year. 


\section{Chapter 6}

\section{Implications, Limitations, Future Research, and Conclusions}

\subsection{Implications}

This paper examines the impact of value chains on population health. We also take into consideration the other potential factors that might impact the health of the populations. These factors are attributed to the socio-economic conditions. The socio-economic factors include infrastructure, education, inflation and trade tariffs. The proxies of population health used in our study are infant mortality rate, maternal mortality rate, adolescent birth rate and life expectancy at birth.

In terms of infant mortality rate, countries with better infrastructure experience lower number of infant deaths. This is consistent with the literature which observed a potential impact of infrastructure on infant mortality rate (Ghosh, 2017). Geruso and Spears (2018) also reported similar findings on the impact of infrastructural development on infant mortality rate. Similar positive results were observed for maternal mortality rate which were consistent with the findings of Alkema et al. (2016) and Powell-Jackson et al. (2015). Other two measures of population health used in our study (i.e., life expectancy at birth and adolescent birth rate) also experience the similar relationship with infrastructure. We get some validation that the results are valid based on the studies conducted by Chapman (2019) and Adu Boahen and Yamauchi (2017) which showed a significant impact of infrastructure on life expectancy at birth and adolescent birth rate respectively. Our analysis reveals that significant development in infrastructure improves health of the populations as it improves accessibility to basic amenities. There exists a vital linkage between a country's transportation, power, education and communication infrastructure and health 
(World Health Organization, 2015). Good health is attributed to general education. Increase in educational enrolment rates is attributed to higher income and better quality of living which strengthens the individuals' incentives to invest in their health such as investing in better food and nutrition (Babiarz et al., 2015). Our analysis resulted in a positive and significant relationship between education population health. Our findings are consistent with those of Goldin and Reinert (2006), UNICEF (2008), Ahmed et al. (2010), Ester et al. (2011), Ikeda et al. (2011), Kuruvilla et al. (2014), Afnan-Holmes et al. (2015), and Adu Boahen and Yamauchi (2017). Other socioeconomic factors used in our analysis were trade tariffs and inflation. Trade liberalization is associated with both social and economic determinants of health. Liberalization of trade improves access to education, income, safe and clean water, and sanitation and nutrition (World Health Organization and World Trade Organization, 2002). We observe a significant impact of trade on population health determinants. The findings of the impact of trade on population health outcomes reported in our study are consistent with Bombardin and Li (2016) and Pierce and Schott (2016), who reported that reduction in trade tariffs resulted in healthier life of the population. We noticed that the individuals in countries with higher tariffs imposed on goods experienced poor health as compared to individuals in countries with lower tariff rates. This is because lower tariff rates improve access to essential medicines and facilitates technology transfer (Blouin et al., 2005). Reduction in trade tariffs result in the drop in prices of goods and services and provides greater access to nutrition, clean water and sanitation which are considered as prominent determinants of population health (World Health Organization and World Trade Organization, 2002).

We also observed a negative but insignificant relationship between inflation and population health. The results are consistent with those of (Li \& Zou., 2002). Inflation has a negative but insignificant effect on the income share of the poor. Inflation wipes out the savings of middle-class people. But 
poor people pay an insignificant portion of their income share to rise in inflation (Cardoso, 1992). This is because the poorest quintile of the population was already poor before the onset of inflation. The lowest quintile of the population does not have any savings and lose an insignificant portion of their income share (less than 1\%) (Cardoso, 1992).

It is important to note that a significant impact of Universal Health Coverage on the population health determinants have been identified: The higher the coverage of basic health facilities in a country, the better is the health of the population. This can be attributed to the fact that Universal Health Coverage provides access to the basic health care necessities to all the individuals without any financial barrier. The goal of Universal Health Coverage is to provide affordable health care services to the public with a wide range of income levels (World Health Organization and International Bank for Reconstruction, 2017). Hence, improved access to the health coverage makes health facilities affordable to the general public which means, they could easily access basic facilities such as regular health checkup, medicines, and other child and maternal care facilities. Universal Health Coverage also reduces the out-of-pocket expenditures on health. This means, people could improve their health by investing in health care as well as the basic nutritional requirements.

Lastly, a significant relationship between value chains and health is detected. A positive and significant impact of value chain breadth on population health in the presence of interaction variable (employment rate) suggests that higher the breadth of the value chain of an economy, better is the health of the population. As population health is measured by four potential factors, we observed a positive and significant relationship between value chain breadth and all the four measures of population health. Based on our results we accept our hypothesis that value chains impact population health and the impact is moderated by employment rate. One possible 
explanation of this could be that value chains help in the upgradation of economy (Fang and Yang, 2013). Value Chains involve growth of the firms. Firms could expand labor intensively and capital intensively. If the firm expands labor intensively, it creates employment opportunities which raises the household income of the population (Farole et al., 2018). However, if the firm expands capital intensively through technological intervention, it promotes economic development by improving product quality, quality of services and increased value-added production (Fang and Yang, 2013).

Our study provides an evidence for the managers and policy makers to devise solutions to promote a healthy and quality living through firm or business expansion. The rise in accessibility to economic opportunities such as employment would help in the development of human capital and a healthy population. Furthermore, policymakers could devise mechanisms for expansion of firms in a country with sufficient coverage for Universal Health.

\subsection{Limitations and Future Research}

\subsubsection{Limitations}

There are several limitations worth mentioning. First, it is important to address the limitation of one of the important independent variables. We consider Universal Health Coverage, which is the index available only for the year 2015. Due to limitations of the data available, the same index value was used for the period used in the analysis. Data collection at national level could improve the precision of the analysis and potentially add value to the implications. However, it is not serious concern because the services which make up the index do not change quickly. Second, our major independent variable which forms the core of our study, value chain breadth captures the firms that invest in different parts of the value chain. The data could be differentiated into the firms that grew labor intensively and capital intensively. This could add specification and granularity to the analysis. 
Another limitation that could be attributed to non-availability of data is the quality of healthcare services. Although health systems are not the primary predictors of population health (Blouin et al., 2005), they are crucial determinants for population health. Also, the Universal Health Coverage index takes into account the hospital bed density and health worker density and has been included in the model. However, data availability on the quality of services could significantly contribute to our study.

Besides quality of healthcare services, data availability on self-employment rate could also contribute to the implications. To the best of our knowledge, data on self-employment rate is not available which forms another limitation of our work. The analysis of value chains considers firm or business expansion across the chain. The interaction paramter used in our study, employment rate, considers the people employed in the industry. Consideration of self-employed individuals along with the people employed in industry could add value to the analysis.

\subsubsection{Future Research Directions}

An area of further investigation is to consider the UHC index value for different years. This could be possible if data is made available for different years. This may provide a clear pathway for a country to invest in different healthcare domains to achieve the required Universal Health Coverage index. Based on the data availability, value chain breadth index could be classified based on the firm type and the nature of expansion. This requires extensive and detailed collection of data based on surveys or interviews. Therefore, another aspect that could be considered is to reexamine the impact on population health outcomes based on the classification of value chain breadth index. Another direction for future research is to consider developed nations. Since, developed nations already achieved a threshold value of the Universal Health Coverage index, considering developed nations in a different model can help re-examine the impact of value chains. 
Another factor that could be considered is stagnant inflation or stagflation. The term stagflation relates to stagnant economic growth, high inflation and high unemployment. It can also be explained as slow movement adjustment of wages, prices, output and employment (Brunner et al., 1980). It is a combination of words stagnant and inflation. As reported in the results, increase in inflation had no significant impact on population health outcomes. However, considering stagflation can help re-examine the impact on population health outcomes.

\subsection{Conclusions}

An increased attention has been given to population health by the World Development Organizations. An important focus of this study is the role of value chains in improving health of the population. Value chains capture firm growth to higher levels of the supply chain. Firms investing in higher parts of the chain contribute to health. This is because they help in restructuring the economy (labor intensively and capital intensively) by heavily investing in other parts of the chain. Value chains lead to a development of industrial sector of a country which accounts for economic development, thus, improving quality of life.

Various socio-economic factors impact population health in numerous ways such as by improving the purchasing power of the population, increasing accessibility and providing employment opportunities. For example, an extensive development in infrastructure enhances population health. This is because infrastructure is associated with roads, transport, communication and power which if improved improves availability and accessibility to basic services (Powell-Jackson et al. 2015; Alkema et al., 2016; Geruso and Spears 2018)

Apart from the factors that impact the health of the population, our study provides insights on the importance of Universal Health Coverage in improving health of the populations across developing nations. Universal Health Coverage aims to provide affordable health care facilities by 
reducing the out-of-pocket expenditures of the public. This considerably improves health of the individuals irrespective of the socio-economic factors discussed in this study. All in all, our study examines the role of value chains and Universal Health Coverage in determining population health in presence of various other socio-economic factors. 


\section{APPENDIX}

1. Correlation between variables

\begin{tabular}{|c|c|c|c|c|c|c|c|c|c|c|c|}
\hline & infm & $\mathbf{m m}$ & abr & le & inf & vcb & infla & tarif & per & uhci & er \\
\hline infm & 1.00 & & & & & & & & & & \\
\hline $\mathbf{m m}$ & 0.82 & 1.00 & & & & & & & & & \\
\hline abr & 0.71 & 0.70 & 1.00 & & & & & & & & \\
\hline le & -0.89 & -0.79 & -0.68 & 1.00 & & & & & & & \\
\hline Inf & -0.53 & -0.46 & -0.51 & 0.49 & 1.00 & & & & & & \\
\hline vcb & -0.45 & -0.35 & -0.42 & 0.49 & 0.65 & 1.00 & & & & & \\
\hline infla & 0.02 & 0.04 & 0.05 & -0.08 & -0.02 & -0.07 & 1.00 & & & & \\
\hline tarif & 0.26 & 0.26 & 0.23 & -0.25 & -0.22 & -0.16 & -0.05 & 1.00 & & & \\
\hline per & -0.60 & -0.59 & -0.49 & 0.54 & 0.28 & 0.27 & 0.00 & -0.17 & 1.00 & & \\
\hline uhci & -0.79 & -0.77 & -0.63 & 0.76 & 0.51 & 0.37 & -0.02 & -0.25 & 0.62 & 1.00 & \\
\hline er & -0.64 & -0.64 & -0.66 & 0.62 & 0.49 & 0.39 & -0.05 & -0.13 & 0.37 & 0.62 & 1.00 \\
\hline
\end{tabular}


2. Multicollinearity test

\begin{tabular}{|c|c|c|}
\hline Variable & VIF & 1/VIF \\
\hline uhci & 2.54 & 0.39 \\
\hline inf & 2.17 & 0.46 \\
\hline vcb & 1.82 & 0.55 \\
\hline er & 1.76 & 0.56 \\
\hline per & 1.65 & 0.60 \\
\hline tarif & 1.09 & 0.91 \\
\hline infla & 1.01 & 0.98 \\
\hline Mean VIF & 1.72 & \\
\hline
\end{tabular}

\section{Autocorrelation tests}

\begin{tabular}{r|rrrrrr}
\hline D.res1 & Coef. & Std. Err. & $t$ & $\mathrm{P}>|\mathrm{t}|$ & [958 Conf. Interva1] \\
\hline $\begin{array}{r}\text { res1 } \\
\text { L1. }\end{array}$ & -.1480157 & .016871 & -8.77 & 0.000 & -.1811467 & -.1148847 \\
& & & & & & \\
\hline cons & -1.542861 & .2737856 & -5.64 & 0.000 & -2.080515 & -1.005206 \\
\hline
\end{tabular}

\begin{tabular}{|r|rrrrrr}
\hline \multicolumn{1}{|c}{ D.res2 } & Coef. & Std. Err. & $t$ & $\mathrm{p}>|\mathrm{t}|$ & [95\& Conf. Interval] \\
\hline $\begin{array}{r}\text { res2 } \\
\text { L1. }\end{array}$ & -.2705158 & .0256372 & -10.55 & 0.000 & -.3208617 & -.22017 \\
& & & & & & \\
\hline cons & 1.348133 & 3.805136 & 0.35 & 0.723 & -6.124313 & 8.820579 \\
\hline
\end{tabular}




\begin{tabular}{r|rrrrrr}
\hline D.res3 & Coef. & Std. Err. & $t$ & $\mathrm{P}>|\mathrm{t}|$ & [958 Conf. Interval] \\
\hline res3 & & & & & & \\
L1. & -.0291395 & .0066367 & -4.39 & 0.000 & -.0421725 & -.0161064 \\
& & & & & & \\
_cons & -.481274 & .1789551 & -2.69 & 0.007 & -.8327022 & -.1298458 \\
\hline
\end{tabular}

\begin{tabular}{r|rrrrrr}
\hline D.res4 & Coef. & Std. Brr. & t & p $>|t|$ & [958 Conf. Interval] \\
\hline res4 & & & & & & \\
L1. & -.0974278 & .0130011 & -7.49 & 0.000 & -.1229591 & -.0718966 \\
& & & & & & \\
_cons & .4551371 & .0749648 & 6.07 & 0.000 & .3079227 & .6023515 \\
\hline
\end{tabular}

\section{Calculation of value chain breadth index}

\section{Box 1: Country score calculation}

This box presents the method applied to compute the scores for the vast majority of economies included in The Global Competitiveness Report 2017-2018 (see text for exceptions).

For any given Survey question $i$, country c's final score, $q_{i c}^{2016-17}$, is given by:

$$
q_{i c}^{2016-17}=w_{c}^{2016} \times q_{i c}^{2016}+w_{c}^{2017} \times q_{i c}^{2017}
$$

where

$$
\begin{aligned}
& q_{i, s}^{t} \text { is country c's score on question } i \text { in year } t \text {, with } t=2016,2017 \text {, as computed following the } \\
& \text { approach described in the text; and } \\
& W_{c}^{t} \text { is the weight applied to country c's score in year } t \text { (see below). }
\end{aligned}
$$

The weights for each year are determined as follows:

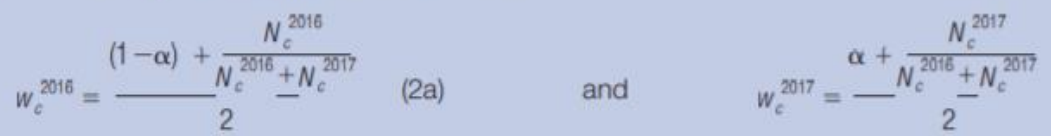

where $N_{c}^{\prime}$ is the sample size (i.e., the number of respondents) for country $c$ in year $t$, with $t=2016,2017$. $\alpha$ is a discount factor. Its value is set at 0.6 . That is, the 2016 score of country $c$ is given $2 / 3$ of the weight given to the 2017 score.

Plugging Equations (2a) and (2b) into (1) and rearranging yields:

$$
q_{i e}^{2016-17}=\frac{1}{2} \times[\underbrace{(1-\alpha) \times q_{i s}^{2016}+\alpha \times q_{i e}^{2017}}_{\text {discounted-past weighted average }}]+\frac{1}{2} \times[\underbrace{\frac{N_{c}^{2016}}{N_{c}^{2016}+N_{c}^{2017}} \times q_{i e}^{2016}+\frac{N_{c}^{2017}}{N_{c}^{2016}+N_{c}^{2017}} \times q_{i c}^{2017}}_{\text {sample-size weighted average }}] .
$$

In Equation (3), the first component of the weighting scheme is the discounted-past weighted average. The second component is the sample-size weighted average. The two components are given half-weight each. One additional characteristic of this approach is that it prevents a country sample that is much larger in one year from overwhelming the smaller sample from the other year. 


\section{Calculation of Universal Health Coverage index}

Reproductive, maternal, newborn, and child - Family planning (FP)

- Antenatal care, four or more visits (ANC)

- Immunisation (DTP3)

- Child care seeking suspected pneumonia (PNEUMONIA)

Infectious disease control

- Tuberculosis effective treatment (TB)

- HIV antiretroviral treatment (ART)

- Insecticide-treated bednets (ITN)

- At least basic sanitation (WASH)

Non-communicable diseases

- Non-raised blood pressure (BP)*

- Mean fasting plasma glucose (FPG):

- Cervical cancer screening"

- Non-use of tobacco (Tobacco)

Service capacity and access

- Hospital bed density (Hospital)

- Health worker density (HWD)

- Access to essential medicines

- IHR core capacity index (IHR)
RMNCH $=(\text { FP } \cdot \text { ANC } \cdot \text { DTP3 } \cdot \text { PNEUMONIA })^{2 / 4}$

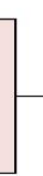

Infectious $=(\text { ART } \cdot \text { TB } \cdot \text { WASH } \cdot \text { ITN })^{2 / 4}$ if high malaria risk

infectious $=(\text { ART } \cdot \mathrm{TB} \cdot \text { WASH })^{1 / 3}$

if low malaria risk

1

$N C D=(B P \cdot F P G \cdot T o b a c c o)^{1 / 3}$
UHC senvice coverage index $=$

(RMNCH - infectious . NCD . Capacity) $)^{1 / 4}$

Capacity $=(\text { Hospital } \cdot H W D \cdot 1 H R)^{2 / 3}$ 


\section{References}

Adu Boahen, E., \& Yamauchi, C. (2017). The effect of female education on adolescent fertility and early marriage: Evidence from free compulsory universal basic education in Ghana. Journal of African Economies, 227-248.

Afnan-Holmes, H., Magoma, M., John, T., Levira, F., Msemo, G., Armstrong, C., \& Rusibamayila, N. (2015). Tanzania's countdown to 2015: an analysis of two decades of progress and gaps for reproductive, maternal, newborn, and child health, to inform priorities for post-2015. The Lancet Global Health, 396-409.

Agénor, P., \& Moreno-Dodson, B. (2006). Public infrastructure and growth: New channels and policy implications. The World Bank.

Ahmed, S., Creanga, A., Gillespie, D., \& Tsui, A. (2010). Economic status, education and empowerment: implications for maternal health service utilization in developing countries. PloS one.

Ainamo, A. (1997). The evolution of the Finnish system of innovation: The contribution of Nokia Competing from the Periphery. Dryden Press, Ireland.

Alkema, L., Chou, D., Hogan, D., Zhang, S., Moller, A., Gemmill, A., \& Say, L. (2016). Global, regional, and national levels and trends in maternal mortality between 1990 and 2015, with scenario-based projections to 2030: a systematic analysis by the UN Maternal Mortality Estimation Inter-Agency Group. The Lancet, 462-474.

Aschauer, D. (2000). Public capital and economic growth: issues of quantity, finance, and efficiency. Economic Development and Cultural Change, 391-406.

Babiarz, K., Eggleston, K., Miller, G., \& Zhang, Q. (2015). An exploration of China's mortality decline under Mao: A provincial analysis, 1950-80. Population studies, 39-56.

Bloom, D., \& Canning, D. (2009). Population health and economic growth. Health and growth.

Blouin, C., Drager, N., \& Smith, R. (2005). International trade in health services and the GATS: current issues and debates. The World Bank.

Bombardini, M., \& Li, B. (2016). Trade, pollution and mortality in china. National Bureau of economic research.

Burdekin, R., Denzau, A., Keil, M., Sitthiyot, T., \& Willett, T. (2004). When does inflation hurt economic growth? Different nonlinearities for different economies. Journal of Macroeconomics, 519-532.

Calderón, C., \& Servén, L. (2004). The effects of infrastructure development on growth and income distribution. The World Bank.

Cardoso, E. (1992). Inflation and poverty. National Bureau of Economic Research. 
Chapman, J. (2019). The contribution of infrastructure investment to Britain's urban mortality decline, 1861-1900. The Economic History Review, 233-259.

Daily, B. N. (2019, August 28). Business News Daily. Retrieved from Business News Daily: https://www.businessnewsdaily.com/5678-value-chain-analysis.html

Dash, R., \& Sahoo, P. (2010). Economic growth in India: the role of physical and social infrastructure. Journal of Economic Policy Reform, 373-385.

De Vogli, R., Mistry, R., Gnesotto, R., \& Cornia, G. (2005). Has the relation between income inequality and life expectancy disappeared? Evidence from Italy and top industrialised countries. Journal of Epidemiology \& Community Health, 158-162.

Easterly, W., \& Bruno, M. (1999). Inflation crises and long-run growth. The World Bank.

Ester, P., Torres, A., Freire, J., Hernández, V., \& Gil, A. (2011). Factors associated to infant mortality in Sub-Saharan Africa. Journal of public health in Africa.

Fang, C., \& Yang, D. (2013). The changing demand for human capital at China's new stage of development.

Faria, J., \& Carneiro, F. (2001). Does high inflation affect growth in the long and short run? Journal of applied economics, 89-105.

Farole, T., Sanchez Puerta, M. L., Canut, A. S., \& Rizvi, A. (2018). Jobs in Value Chains Survey Toolkit. Washington, DC: World Bank.

Friel, S., Hattersley, L., Snowdown, W., Thow, A., Lobstein, T., Sanders, D., \& Kumanyika, S. (2013). Monitoring the impacts of trade agreements on food environments. obesity reviews, 120-134.

Geruso, M., \& Spears, D. (2018). Neighborhood sanitation and infant mortality. American Economic Journal: Applied Economics, 125-162.

Ghosh, M. (2017). Infrastructure and Development in Rural India. Margin: The Journal of Applied Economic Research, 256-289.

Goldin, I., \& Reinert, K. (2006). Globalization for development: trade, finance, aid, migration, and policy. The World Bank.

Goodman , N. (2015). The impact of employment on the health status and health care costs of workingage people with disabilities. Lead Center Policy Brief.

Government of Canada. (2008, June 06). Retrieved from Statistics Canada: https://www.canada.ca/en/public-health/corporate/publications/chief-public-health-officerreports-state-public-health-canada/report-on-state-public-health-canada-2008/chapter-3c.html

Government of Canada. (2016, December 15). Health Status of Canadians 2016: Report of the Chief Public Health Officer - How healthy are we? - Life expectancy at birth. Retrieved from https://www.canada.ca/en/public-health/corporate/publications/chief-public-health-officerreports-state-public-health-canada/2016-health-status-canadians/page-4-how-healthy-are-welife-expectancy-birth.html 
Gujarati, D. (2003). Basic Econometrics. Forth Edition. Singapura: McGraw-Hill.

Gujarati, D., \& Porter, D. (2009). Basic econometrics (5th ed.). McGraw-Hill Irwin.

Ha, J., Kose, M., \& Ohnsorge, F. (2019). Inflation in Emerging and Developing Economies: Evolution, Drivers, and Policies. World Bank Publications.

Hogan, D. R., Stevens, G. A., Hosseinpoor, A. R., \& Boerma, T. (2018). Monitoring universal health coverage within the Sustainable Development Goals: development and baseline data for an index of essential health services. The Lancet Global Health , 152-168.

Ikeda, N., Saito, E., Kondo, N., Inoue, M., Ikeda, S., Satoh, T., \& Noda, M. (2011). What has made the population of Japan healthy? The Lancet, 1094-1105.

Johansson, S. (1991). The health transition: the cultural inflation of morbidity during the decline of mortality. Health transition review, 39-68.

Johnstone, N., \& Labonne, J. (2004). Generation of household solid waste in OECD countries: an empirical analysis using macroeconomic data. Land Economics, 529-538.

Judge, K. (1995). Income distribution and life expectancy: a critical appraisal. Bmj, 1282-1285.

Judge, K., Mulligan, J., \& Benzeval, M. (1998). Income inequality and population health. Social Science \& Medicine, 567-579.

Kuruvilla, S., Schweitzer, J., Bishai, D., Chowdhury, S., Caramani, D., Frost, L., \& Cohen, R. (2014). Success factors for reducing maternal and child mortality. Bulletin of the World Health Organization.

Leigh, J. (1983). Direct and indirect effects of education on health. Social Science \& Medicine, 227-234.

Leipziger, D., Fay, M., Wodon, Q., \& Yepes, T. (2003). Achieving the millennium development goals: the role of infrastructure. The World Bank.

Levine, D., \& Rothman, D. (2006). Does trade effect child health. Journal of Health Economics, 538-554.

Li, H., \& Zou., H. (2002). Inflation, growth, and income distribution: A cross-country study. Annals of Economics and Finance, 85-101.

Linn, M., Sandifer, R., \& Stein, S. (1985). Effects of unemployment on mental and physical health. American Journal of Public Health, 502-506.

Liu, Q., Okui, R., \& Yoshimura, A. (2016). Generalized least squares model averaging. Econometric Reviews, 1692-1752.

London: Office for National Statistics. (2003). Life expectancy at birth: methodological options for small populations. London: Office for National Statistics.

Marmot, M., Friel, S., Bell, R., Houweling, T., Taylor, S., \& Health, C. o. (2008). Closing the gap in a generation: health equity through action on the social determinants of health. The lancet, 16611669. 
Mathews, T., MacDorman, M., \& Thoma, M. (2015). Infant mortality statistics from the 2013 period linked birth/infant death data set. Centres for disease control and prevention.

Mingat, A., \& Majgaard, K. (2012). Education in Sub-Saharan Africa: A Comparative Analysis. The World Bank.

Navarro, V., Muntaner, C., Borrell, C., Benach, J., Quiroga, A., Rodríguez-Sanz, M., \& Pasarín, M. (2006). Politics and health outcomes. The Lancet, 1033-1037.

New Jersey Department of Health. (2019, July 10). Retrieved from New Jersey State Health Assessment Data: https://www-doh.state.nj.us/doh-shad/indicator/view/EPHTInfMort.NJ.html

Organization, W. H. (2015). Global reference list of 100 core health indicators (No. WHO/HIS/HSI/2015.3). World Health Organization.

Padovano, F., \& Galli, E. (2001). Tax rates and economic growth in the OECD countries. Economic Inquiry, 44-57.

Pampel, F., \& Pillai, V. (1986). Pattens and determinants of infant mortality in developed nations. Demography, 525-542.

Panda, P. (2015). Essays on Trade, Infrastructure and Human Capital Outcomes in Developing Countries. UC Riverside.

Petrosino, A., Morgan, C., Fronius, T., Tanner-Smith, E., \& Boruch, R. (2012). Interventions in developing nations for improving primary and secondary school enrollment of children: A systematic review. Campbell Systematic Reviews.

Pierce, J., \& Schott, P. (2016). Trade liberalization and mortality: Evidence from US countries. National Bureau of Economic Research.

Powell-Jackson, T., Gao, Y., Ronsmans, C., Zhou, H., Wang, Y., \& Fang, H. (2015). Health-system determinants of declines in maternal mortality in China between 1996 and 2013: a provincial econometric analysis. The Lancet, 386.

Ross, C., \& Mirowsky, J. (1995). Does employment affect health? Journal of Health and social Behavior, 230-243.

Ross, C., \& Wu, C. (1995). The links between education and health. American sociological review, 719745.

Schwab, K. (2012). The Global Competitiveness Report 2012-2013. Geneva: World Economic Forum.

Shandra, J., Nobles, J., London, B., \& Williamson, J. (2004). Dependency, democracy, and infant mortality: a quantitative, cross-national analysis of less developed countries. Social science \& medicine, 321-333.

Smith, R. (2006). Measuring the globalization of health services: a possible index of openness of country health sectors to trade. Health Economics, Policy and Law, 323-342. 
Snieška, V., \& Šimkūnaitè, I. (2009). Socio-economic impact of infrastructure investments. Inžinerine ekonomika, 16-25.

The United Nations. (n.d.). Retrieved from https://www.un.org/en/development/desa/policy/wesp/wesp_current/2014wesp_country_clas sification.pdf

The World Bank. (2019). Inflation in Emerging and Developing Economies. Retrieved from https://www.worldbank.org/en/research/publication/inflation-in-emerging-and-developingeconomies

The World Bank. (2019, April 17). REPRODUCTIVE, MATERNAL, NEWBORN, CHILD, AND ADOLESCENT HEALTH. Retrieved from https://www.worldbank.org/en/topic/reproductivematernalchildhealth

The World Bank. (n.d.). The World Bank. Retrieved from http://datatopics.worldbank.org/worlddevelopment-indicators/themes/people.html

The World Bank. (n.d.). The World Bank/ Data. Retrieved from https://data.worldbank.org/indicator

The World Bank/data. (n.d.). Retrieved from https://data.worldbank.org/indicator/SL.IND.EMPL.ZS

UNESCO. (2007). Education for All Global Monitoring Report 2008: Education for All by 2015. Will We Make It? Oxford University Press.

UNICEF. (2008). The state of the world's children 2009: maternal and newborn health (Vol. 9). Unicef.

Vu, T., Gangnes, B., \& Noy, I. (2008). Is foreign direct investment good for growth? Evidence from sectoral analysis of China and Vietnam. Journal of the Asia Pacific Economy, 542-562.

WHO, UNICEF, UNFPA, World Bank Group, \& United Nations Population Division. (2019). Maternal mortality: Levels and trends 2000 to 2017.

Wilkinson, R., \& Marmot, M. (2003). Social determinants of health: the solid facts. World Health Organization.

World Bank. (2007). Global Monitoring Report 2007 : Millennium Development Goals, Confronting the Challenges of Gender Equality and Fragile States. World Bank.

World Bank. (2017). The Global Competitiveness Report 2017-2018. Geneva: World Economic Forum.

World Bank Blogs. (n.d.). Retrieved from https://blogs.worldbank.org/opendata/despite-remarkableprogress-15000-children-and-800-women-still-die-every-day-mostly

World Bank, I. M. (2012). Global Monitoring Report 2012 : Food Prices, Nutrition, and the Millennium Development Goals. The World Bank.

World Health Organization. (2002). The world health report 2002: reducing risks, promoting healthy life. World Health Organization.

World Health Organization. (2005). The World Health Report 2005: Make Every Mother and Child Count. Geneva, Switzerland: World Health Organization. 
World Health Organization. (2013). Adolescent Fertility Rate. Retrieved from http://origin.who.int/healthinfo/indicators/2015/chi_2015_37_fertility_adolescent.pdf

World Health Organization. (2015). Global Health Observatory (GHO) data. Retrieved from https://www.who.int/gho/publications/mdgs-sdgs/MDGsSDGs2015_chapter4_snapshot_newborn_health.pdf?ua=1

World Health Organization. (2015). Global reference list of 100 core health indicators. World Health Organization.

World Health Organization. (2015). Strategies towards ending preventable maternal mortality (EPMM).

World Health Organization. (2016). Global Strategy for Women's, Children's and Adolescents' Health (2016-2030). Retrieved from http://apps.who.int/gho/data/node.gswcah

World Health Organization. (2016). WHO statistical information system. Retrieved from World Health Organization: https://www.who.int/whosis/indicatordefinitions/en/

World Health Organization and International Bank for Reconstruction. (2017). Tracking Universal Health Coverage:2017 Global Monitoring Report. Switzerland: The World Bank.

World Health Organization and World Trade Organization. (2002). Agreements and Public Health: A Joint Study by the WHO and WTO Secretariat. WHO/WTO.

World Health Organization. (n.d.). Global Health Observatory (GHO) data. Retrieved from https://www.who.int/gho/mortality_burden_disease/life_tables/situation_trends_text/en/

World Health Organization. (n.d.). World Health Organization. Retrieved from Global Health Observatory indicator views: http://apps.who.int/gho/data/node.imr.MDG_0000000003?lang=en

Yaffee, R. (2003). A primer for panel data analysis. Connect: Information Technology at NYU, 1-11. 